\title{
Taking Advantage of the Genomics Revolution for Monitoring and Conservation of Chondrichthyan Populations
}

\author{
Shaili Johri ${ }^{1}$, Michael P. Doane ${ }^{1,2}$, Lauren Allen ${ }^{1}$ and Elizabeth A. Dinsdale ${ }^{1, *}$ \\ 1 Department of Biology, San Diego State University, 5500 Campanile Dr., San Diego, CA 92128, USA; \\ sjohri@sdsu.edu (S.J.); michael.doane@sims.org.au (M.P.D.); allen.college.lauren96@gmail.com (L.A.) \\ 2 Sydney Institute of Marine Sciences, 19 Chowder Bay Rd, Mosman, NSW 2095, Australia \\ * Correspondence: edinsdale@mail.sdsu.edu
}

Received: 5 February 2019; Accepted: 21 March 2019; Published: 29 March 2019

\begin{abstract}
Chondrichthyes (sharks, rays, skates and chimaeras) are among the oldest extant predators and are vital to top-down regulation of oceanic ecosystems. They are an ecologically diverse group occupying a wide range of habitats and are thus, exploited by coastal, pelagic and deep-water fishing industries. Chondrichthyes are among the most data deficient vertebrate species groups making design and implementation of regulatory and conservation measures challenging. High-throughput sequencing technologies have significantly propelled ecological investigations and understanding of marine and terrestrial species' populations, but there remains a paucity of NGS based research on chondrichthyan populations. We present a brief review of current methods to access genomic and metagenomic data from Chondrichthyes and discuss applications of these datasets to increase our understanding of chondrichthyan taxonomy, evolution, ecology and population structures. Last, we consider opportunities and challenges offered by genomic studies for conservation and management of chondrichthyan populations.
\end{abstract}

Keywords: sharks; conservation; genomics; monitoring; metagenomics

\section{Introduction}

Next-generation sequencing (NGS) technologies have revolutionized biological sciences by allowing unprecedented access to a wide range of genome data for model and non-model plant, animal and microbial species [1-7]. Genetic and genomic data for non-model species, has significantly advanced ecological investigations in terrestrial and marine environments by identifying new species [8], understanding ecological interactions [6,9], and exploring evolutionary relationships between species $[10,11]$. In spite of the phenomenal advances in ecological genomics, Chondrichthyes, one of the most important species groups for top-down regulation of oceanic ecosystems remain understudied.

Chondrichthyes, consisting of sharks, rays, skates and chimaeras, are one of the oldest extant vertebrate lineages with high interspecies diversity in ecology and demographics (Compagno, 1990; Kriwet et al., 2008) [12] and vast evolutionary distances between the 1200 chondrichthyan species [13]. Chondrichthyes have extraordinary wound healing and immune capabilities [14-16], high genome-stability [14], and a wide range of reproductive strategies $[14,17,18]$. With high divergence among chondrichthyan species, all or part of these adaptations may contribute to survival strategies during their long life histories and may contribute to evolutionary success to a differing extent in each species. Chondrichthyan genomes, therefore provide an excellent opportunity to study mechanisms that contribute to evolutionary resilience, and to understand mechanisms of genome 
stability, extraordinary immunological capacity and resilience among megafauna with long life histories in general.

Although evolutionarily resilient, most Chondrichthyes today face an unprecedented population decline, due to elevated fishing pressure [19] and slow life history traits [20], which make population recovery difficult. Small species populations suffer from inbreeding and genetic drift, leading to a loss of genetic diversity. These processes compromise the ability of a population to evolve in order to cope with environmental changes and reduce its chances of long-term persistence. Different species need to be studied at a different resolution to determine the most efficient conservation strategy. Migratory oceanic species tend to have more homogeneous populations [21], whereas smaller, more coastal species, often exist in isolated populations [22]. These coastal species tend to experience more obstacles, such as marine barriers to gene flow and therefore, assessing the extent of genetic diversity throughout their distribution is imperative to avoid local gene pool erosion. Second, it is important to understand if phenotypic changes in a population indicate an evolutionary response to overfishing and if these pressures affect all or part of the species' population and any existing population structure. Such information is important for identification of evolutionary units and with respect to conservation management of the population. Further, these studies increase our understanding of evolutionary processes among marine megafauna under anthropogenic pressure. For example, the high agility and burst swimming behavior that supports prey capture strategy of hammerhead sharks, a trait that once promoted evolutionary success, also results in a $60-80 \%$ rate of post-release mortality [23]. Although the role of overexploitation on evolution in Chondrichthyes is yet to be explored, such examples suggest that evolutionarily beneficial traits and unique adaptations can be affected by overexploitation

Chondrichthyes play an important role in top-down regulation of oceanic ecosystems [24] and yet, an estimated $46.8 \%$ chondrichthyan species worldwide are data deficient [19]. With almost half of all Chondrichthyes being data deficient, critical data required for conservation and management of these species are often missing and limit conservation efforts. As a result, effects of population decline are of major concern not only for the conservation and management of Chondrichthyes but for overall conservation of the oceanic ecosystem. Therefore, a greater and urgent push for comprehensive studies that aim to understand species biodiversity, intra-species genetic diversity and ecological exchangeability of particularly exploited populations, population abundance, and population health, is impending. We explore a range of genome sequencing methods and suggest avenues to incorporate genomic data in research to reducing data deficiencies in Chondrichthyes.

Advancement in marine ecological studies resulting from the use of molecular genetics and genomes have been reviewed extensively for other species groups [25-27]. Chondrichthyes have been overlooked even in studies focusing on fisheries and fish ecology $[25,27]$ even though Chondrichthyes form a significant volume of commercial fisheries and are the most data deficient and threatened species groups [19]. In this article we explore high-throughput next-generation sequencing methods to acquire genomic and microbial metagenomics data from Chondrichthyes. We discuss the application of these data sets to facilitate increased understanding of chondrichthyan populations, ecology, evolution and biology. We also explore the application of genomic studies to reduce data deficiency of Chondrichthyes and to facilitate identification and improved conservation management of priority concern units. The article advances an earlier review of traditional molecular genetics methods for chondrichthyan biodiversity assessments by Dudgeon et al., 2012 [28].

\section{Genetics and Genomics for Chondrichthyan Biodiversity Assessments}

\subsection{Taxonomy, Phylogenetics and Population Genetics: Limitations of Single Genetic Markers}

Mitochondrial and nuclear genetic markers acquired through amplification-based assays are widely used for taxonomic identification, phylogenetics and population genetic assessments in Chondrichthyes. These marker-based studies have helped generate a wealth of biodiversity data which forms the backbone of chondrichthyan biodiversity research today. While these methods have 
supported chondrichthyan research and conservation efforts till date, they are restricted in some aspects and may not meet all the needs of a comprehensive and effective conservation regime that is urgently required for protection of remaining chondrichthyan populations. Genetic markers and their applications to chondrichthyan biodiversity assessments have been extensively reviewed by Dudgeon et al., 2012 [28]. In this section we will discuss some of the limitations of single marker studies in comparison to multigenic approaches.

DNA barcoding provides a quick turnaround tool for species identification of a wide range of organisms [29]. The mitochondrial Cytochrome oxidase 1 encoding gene (COI, $660 \mathrm{bp}$ ) is primarily used for barcoding studies and involves PCR amplification of the complete or partial gene fragment from genomic DNA (gDNA) extracts followed by sequencing and alignment to a reference database for taxonomic identification. Full length or short gene fragments of the COI DNA barcode are widely used for species identification of Chondrichthyes in forensic and ecological investigations [30-33]. Markers used as alternatives to COI, include the NADH dehydrogenase subunit 2 (NADH2) [34,35], NADH dehydrogenase subunit 4 gene [36,37], 12S and 16S ribosomal RNA [38], and the nuclear Internal Transcribed Spacer region [39].

Many genetic markers have been developed to study wildlife species in general or specifically to study Chondrichthyes and have been reviewed by Dudgeon et al., 2012 [28]. Although these markers have been used, in singularity, for taxonomy, populations studies and phylogenetics, they are limited in their application, due to one or more of the following: Multiple chondrichthyan species have identical marker sequences [30], variation in sequences occurs between the same nominal species from geographically different locations [40], and non-amplification of barcode sequences from undescribed species using universal primers may occur [35,41]. Use of single markers can also prevent the detection of processes such as interspecies hybridization. For example, a set of chondrichthyan specimens from C. limbatus and C. tilstoni did not match with respect to their taxonomic identities based on morphology and molecular identification with mitochondrial ND4. Morphological characteristics typed the specimen as $C$. limbatus but the ND4 mtDNA assay identified them as $C$. tilstoni. Interspecies hybridization between C. tilstoni and C.limbatus was hypothesized as the reason for mismatches. Analyses of a nuclear microsatellite marker, indeed identified interspecies hybridization between the two species. These discrepancies, if undetected could lead to misidentification of species, lack of detection of interspecies interactions and inaccurate biodiversity assessments. Johri et al., 2019 [42] were unable to determine taxonomic identification of a dismembered shark specimen based on morphology or COI barcode analyses, due to identical sequences for four different Carcharhinid species. Sequencing and comparison of thirteen protein coding genes of the mitochondria and the ITS2 nuclear loci led to determination of taxonomic identity of the specimen as Carcharhinus falciformis (silky shark). These scenarios, which are a common occurrence in chondrichthyan studies, make taxonomic identification based on morphology only or one genetic marker only, unreliable and highlight the importance of multigenic taxonomic assessments for accurate taxonomic identification and for the detection of biological processes occurring among Chondrichthyes.

Phylogenetic assessment of smooth-tooth sharks (Carcharhinus leiodon) [40] using two distinct mitochondrial markers, COI and ND2, led to broadly consistent, but non-identical results. The ND2 neighbor-joining-tree revealed each species to be monophyletic, whereas COI analyses failed to group all C. amblyrhynchoides individuals into the same cluster [40]. In the study of Carcharhinid sharks by Johri et al., 2019 [42], phylogenetic relationships of 33 Carcharhinus species, including Prionace glauca were reassessed using two mitochondrial and one nuclear genes. These multigenic assessments corroborated previous studies [43], which provided weak support, based on single gene analyses, for the inclusion of P. glauca in the Carcharhinus genus. These data underscore the need for multiple genetic markers from the mitochondrial and nuclear genomes for accuracy and higher statistical power in phylogenetic studies.

Mitochondrial and nuclear microsatellite markers, the latter being among hypervariable regions of the genome, are often used to determine gene flow, genetic differentiation and population structure 
in Chondrichthyes. Microsatellites allow analyses of neutral, and in rare cases, adaptive genetic variations in a population [44] to be assessed based on a select set of well characterized species-specific markers. Microsatellites remain an economical and targeted tool for studying populations, and for conservation and management of populations.

Population structure was determined among elasmobranchs such as the basking shark (Cetorhinus maximus) [45] and pacific blue shark (Prionace glauca) [21] using the mitochondrial control region $(C R)$ and these studies identified low divergence in populations. Investigations of the nurse shark (Ginglymostoma cirratum) [46,47], great white shark (Carcharodon carcharias) [48,49], coastal blacktip shark (Carcharhinus limbatus) [50], and bull shark (Carcharhinus leucas) [51] populations using the mitochondrial $C R$ region revealed high divergence in populations. In contrast, analyses of microsatellite loci in the nurse shark and great white shark populations provided no evidence of genetic subdivisions [48,51]. Although further investigation is warranted, natal philopatry in females may explain the discrepancy in results derived from two different categories of markers. Tillett et al., 2012 [52] also found contrasting results with respect to population structure in the pig-eye shark (Carcharhinus amboinensis) using mitochondrial (CR and NADH dehydrogenase subunit 4 (NADH4)) and nuclear (microsatellite and RAG1) DNA. Mitochondrial DNA supported the existence of two populations whereas nuclear DNA analyses suggested one homogenous population. Although it remains to be tested, female philopatry or episodic isolation and connection of populations, due to sea level changes in the past may explain discrepancies in the two analyses.

Population genetic analyses of the scalloped hammerhead shark (Sphyrna lewini) and the portuguese dogfish (Centroscymnus coelolepis) using both, mitochondrial (NADH4 and CR regions) and nuclear microsatellites revealed similar results where non-significant genetic differentiation and genetic homogeneity was observed in populations for both species [53,54]. Similarly, analyses of spiny dogfish (Squalus acanthias) populations using both, mitochondrial ND2 and nuclear microsatellites revealed comparable results with two genetically distinct groups, one in the North Pacific and one in the South Pacific and Atlantic locations [55]. Last, investigations of the tope shark (Galeorhinus galeus) populations using 19 microsatellite and mitochondrial CR identified limited transoceanic gene flow and significant population structure [56]. However, significant population connectivity was seen at a smaller spatial scale within the Indian ocean and moderate to high gene flow was supported across Indian/Atlantic Ocean boundary in South African populations [56]. Because the tope shark is a highly exploited species these data provide timely direction for local and global management of G. galeus. At a large spatial scale, populations comprise distinct genetic groups and thus replenishment of the Pacific vs. Indian/Atlantic Ocean population will need to occur with input from spatially indistinct populations only.

The aforementioned case studies underscore the challenges associated with obtaining accuracy in taxonomic identification, phylogenetic analyses and population genetic analyses using single genetic markers. These studies also highlight the importance of using a multigenic approach that relies on mitochondrial and nuclear markers for taxonomic, phylogenetic and population genetic studies. Assessment of a large set of mitochondrial and nuclear markers allows multiple opportunities to determine taxonomic identification of a specimen, therefore providing increased accuracy and confidence in the analyses. Multigenic population assessments improve on single gene assessments by differentiating shallow intraspecific divergence from true genetic differentiation and population structure in populations. A multigenic approach will also improve gene tree vs. species tree issues in phylogenetic analyses and if selected carefully, the markers should provide the true evolutionary history of the species.

\subsection{Population Genomics and Implications for Chondrichthyan Conservation and Management}

Populations of a single species can be structured or synonymous across geographic ranges. Genetically divergent sub-populations have distinct geographic ranges, population size and habitat preferences as opposed to synonymous populations which have similar ecological traits. To facilitate 
protection of all genetically distinct sub-populations and evolutionary significant units (ESUs) of a species, and to maintain genetic diversity within each sub-population, understanding of population genetics is necessary to first, assess presence or absence of population structure, decipher effective population size and health of each genetic group and last, to use these metrics in identifying vulnerabilities and stressors associated with each population of a species. ESUs are defined as geographically separated populations of the same species, which have genetically differentiated and/or developed phenotypic adaptations different from the parent species, for survival in their relatively new habitat. Genetic diversity and population size of ESUs needs to be maintained in order to preserve the evolutionary potential of a species. These data are crucial for comprehensive and effective conservation and management of vulnerable Chondrichthyes [17,57-59]. With almost half of chondrichthyan species being data deficient [19] expedient and effective methods to obtain population genetic data from all species are required.

Single Nucleotide Polymorphisms (SNPs), alongwith microsatellites are among hypervariable regions of the genome which are used to determine presence or absence of population structure and philopatry, based on gene flow and genetic divergence among wildlife populations. As opposed to microsatellites, which represent neutral variation, SNPs allow both adaptive and neutral genetic variations to be assessed across the genome [44,60]. SNP are distributed across the genome and therefore, SNP analyses provide a genome-wide assessment of individuals in a population, thus a more accurate picture of the presence or absence of genetic differentiation and population structure [60]. Despite the economic advantages that microsatellites offer, the need for genome wide assessments in order to study population structure and evolution in wildlife populations, is making way for SNP analyses. Further, the development of microsatellites for elasmobranch studies remains difficult, due to the need for a species-specific sequence dependent amplification assay to assess microsatellite sequences. Though, microsatellites developed for one species can be leveraged for studies other different species by cross-amplification of microsatellite loci across species. This method has been used successfully in a few elasmobranch studies [61-63], thus allowing reuse of developed microsatellite loci across different species. However, a requirement for a priori sequence information restricts the scope of elasmobranch population studies for new or understudied species using microsatellites. SNPs are a routinely used marker to study wildlife populations for a wide range of applications, including population genetics, individual identification, sex, lineage and philopatry determination [60]. SNP analyses are yet to see mainstream use in chondrichthyan research, however a few groups have used SNPs to determine population structure, dispersal, and philopatry. In the following section we discuss the advantages of population studies based on SNP analyses with respect to ecology and conservation of Chondrichthyes.

SNP analysis of the river shark (Glyphis garricki) mitochondrial genome, discovered previously unknown marine dispersal and gene flow between sharks from different rivers [64]. In addition, a new Glyphis spp. was also discovered [64]. Expanding on the mitochondrial SNP analysis, Momigliano et al., 2017 [65] used a large set of nuclear SNPs and identified cryptic differentiation of adaptive loci in grey reef sharks (Carcharhinus amblyrhynchos). In addition, sex-biased dispersal was also identified using the variation in mitochondrial SNPs, where females moved further compared to males and were responsible for gene-flow between populations. This differentiation in grey reef sharks was previously undetected, due to the use of a small set of neutral markers [65].

Genome wide assessment of 1000s of nuclear and mitochondrial SNPs across individuals of the Galapagos shark (Carcharhinus galapagensis), a priority species in the Galapagos Marine Reserve (GMR) was used to determine population structure, gene flow and effective population size among stocks in the GMR [66]. Although a highly migratory species, two distinct stocks of the Galapagos shark were identified within the GMR. The ability of a few long-distance migrant individuals to sufficiently maintain apparent panmixia [67] explains these results. Identification of the two distinct stocks and small effective population size for each stock, may cause the Galapagos sharks to be vulnerable to anthropogenic and environmental stressors [66]. In the Galapagos shark study the choice of genetic 
loci was limited to neutral loci only. Outlier or adaptive loci, which facilitate detection of fine scale variation and stratification in populations, could not be used due to the absence of a reference genome. Pazmino et al., 2017 [66] confirmed the importance of using a wider range of genomic markers, because the analysis of the mitochondrial DNA showed that the populations were synonymous, whereas nuclear SNPs allowed detection of the extensive population structure in Galapagos sharks. Therefore, inferences of low divergence based on single mitochondrial locus studies of basking sharks and pacific blue shark described above are questioned [28] and should be reexamined using a wider range of markers.

Trans-oceanographic gene flow of the galapagos shark using SNPs identified two distinct populations in the east and west Pacific [68]. The presence of high nucleotide diversity and a high number of haplotypes in the Hawaiian population, suggested Hawaii as an important movement corridor between the east and west populations [68]. The effective population size estimated from population genetic data showed a healthy Galapagos shark sub-population with the optimal breeding capacity and several sub-populations with low carrying capacity, which are in urgent need of regional management [68].

A genome wide SNP assessment in bonnethead sharks (Sphyrna tiburo) provided evidence for population structure and differential philopatry between males and females of the species [69]. Portnoy et al., 2015 [69], identified two distinct populations of bonnethead sharks in the Atlantic and Gulf of Mexico. No gene flow between the Atlantic and Gulf of Mexico populations was detected, whereas high gene flow within the three sub-populations in the Gulf of Mexico was identified. Males contribute to a high rate of gene flow among Gulf of Mexico populations, while female matrilines maintain adaptive alleles in the population evidenced by strong differentiation at a small number of nuclear markers. Additionally, females of the species do contribute to gene flow among neighboring populations based on mitochondrial haplotype analyses, indicating that females don't move away from preferred areas but only to neighboring sites. The study therefore highlighted the role of sex-biased dispersal in spreading adaptive variation and its effects on species survival and persistence [69]. However, the lack of an optimal number of SNPs in protein-coding genes restricts the correlation between attributes such as differences in growth rate and immune function to adaptive variation between populations [69].

Last, benthic species like the small-spotted catshark (Scyliorhinus canicula) have limited ability to disperse and as a result are expected to have strong genetic structure. However, no evidence of genetic structure was found across its geographic range using traditional microsatellite markers. In a ground breaking study Manuzzi et al., 2019 [22] detected fine-scale genetic differentiation between two geographic ranges of the small-spotted catshark using 2674 SNPs generated by $2 b$-restriction site associated DNA sequencing (2b-RAD). Manuzzi et al., 2019 [22] found that the geographical distance and historical demography as two major drivers shaping the distribution of genetic diversity of $S$. canicula. These results provide new insights into the biogeography and population structure of $S$. canicula and serve as a reference for benthic elasmobranchs with similar distribution ranges.

Genome wide SNP assessments of small-spotted catshark, galapagos sharks, and bonnethead sharks were thus employed in determining population structure, philopatry, migration corridors and effective population size for these species. These studies provided crucial data for integration into multispecies assessments of their respective geographic ranges to determine no-take zones. These data will potentially help in relieving fishing pressure from vulnerable populations and in the protection of distinct adaptive units of priority concern species. Nevertheless, the aforementioned studies underscore the importance of high resolution genome-wide assessments for population genetic studies and conservation management of Chondrichthyes.

\subsection{Sequenced Chondrichthyan Genomes and Their Advantages}

To date only 5 of the approximate 1200 chondrichthyan species have fully sequenced genomes. These include the elephant shark (Callorhinchus milii) [18], the whale shark (Rhincodon typus) [70], great 
white shark (Carcharhodon carcharias) [14], brownbanded bamboo shark (Chiloscyllium punctatum) and cloudy catshark (Scyliorhinus torazame) [71]. A sixth species, the silky shark (Carcharhinus falciformis), has a partially sequenced genome [42]. Although, a low number of sequenced genomes suggest the lack of data associated with the group, these sequenced genomes have provided considerable insight into chondrichthyan evolution and physiology, and underscore the importance of genomic studies in Chondrichthyes.

A genome-wide comparison with teleost and tetrapods showed that elephant sharks have the slowest rate of evolution among all fish species, since divergence from the gnathostome ancestor [18]. In a three-way comparison with chicken and teleost fish, the sharks have a one-to-one synteny relationship with chickens, whereas teleost fish display a one to two relationship with the chicken, suggesting the teleost fish have undergone a substantially higher number of interchromosomal rearrangements [18]. In addition, the shark contains a highly restricted subset of T-helper cells, as well as T-cells and unconventional antigen-binding properties, suggesting that the sharks' immune system evolved after they split from a common ancestor [18]. The sequencing of a second chondrichthyan species, the whale shark (Rhincodon typus), further investigated T-cells in the species and identified the presence of novel Toll-like receptors (TLR), that are homologous to mammalian and teleost TLR receptors. The reduced immune function resulting from missing helper and T-cell types in the chondrichthyan genomes explains the long time required for the development of humoral immunity in sharks [72] and raises the question as to how sharks, which are relatively long-lived, fight infection. Understanding the unusual immune capabilities of sharks will provide interesting insights into how the sharks' immune system interacts with their microbiomes and if their physiological mechanisms can be adapted to assist human biomedicine.

Genome-wide analyses of the white shark, whale shark and elephant shark genomes and comparison to non-chondrichthyan genomes by Marra et al., 2019 [14], identified genomic regions under positive selection in sharks. Genes under positive selection in sharks allow increased functional capacity and increased gene content in pathways interacting with the p53 tumor-suppressor gene. The MDM4 gene, which is responsible for direct regulation of p53 levels, was under positive selection, with genetic modifications at its p53 interacting site. Positive selection was also seen among genes responsible for DNA repair and increased genome stability. These findings begin to explain the evolutionary process in Chondrichthyes which imparts them unique immune functions, high genome stability and may assist in survival through their long life histories.

Partial genome sequencing of the silky shark was used to improve the phylogenetic placement of P. glauca with respect to sharks in the Carcharhinus genus [42]. Assessment of nuclear markers in combination with the mitochondrial genome provided stronger evidence for placement of P. glauca within the Carcharhinus genus. The partial sequence also identified previously unexplored regions of the silky shark genome which are involved in development and immune function. Future analyses of these regions will improve our understanding of the silky shark as a prolific and highly migratory species with a wide geographic distribution.

Although more chondrichthyan genomes need to be sequenced in order to improve overall biodiversity assessments among Chondrichthyes, including taxonomic, population and phylogenetic studies, sequencing genomes does not, in itself, resolve all challenges. For example, the integrity and efficiency of species biodiversity assessments are dependent upon the presence of quality genomes and sequences in the reference database(s). In the absence of adequate taxon sampling within reference databases, alignment algorithms are likely to assign samples to the most similar species and increase the likelihood of inaccurate analyses. When using genome wide data, it is however, possible to take advantage of reference sequences for widely-used and curated mitochondrial markers to assign species identities to the sample in question and subsequently scale up the reference database by assigning species designations to previously unexplored genomic regions from the same species. This approach will allow increased use of current databases and building of new reference databases with multiple nuclear and mitochondrial regions for taxonomic identification, phylogenetic analyses, 
population and evolutionary studies. Expanding the available phylogenetic markers available for chondrichthyes through genomic approaches will also provide additional and mainstream usage to rich genomic resources such as sequenced chondrichthyan genomes [14,18,42,70,71]. Availability of additional elasmobranch genomes will significantly improve population genetics and evolutionary studies like those of Pazmiño et al.,2017 [66] and Portnoy et al., 2015 [69]. Both studies were restricted in their inference of linkage between population variance and adaptive changes linked to geographical variation, due to the lack of available protein coding regions in genomes from respective species.

\section{Genomic Assessment Techniques for Chondrichthyan Taxonomic and Population Assessments}

The recent explosion in next-generation sequencing technologies has allowed unprecedented access to genomic data among non-model species and these technologies can be harnessed to access elasmobranch genomes for varied applications such as taxonomic identification, phylogeny and population genetic studies. We will review three genome analyses techniques, including RAD-seq, hybridization-based gene capture and genome skimming in the following section.

\subsection{Sub-Sampling Chondrichthyan Genomes Through Targeted Approaches}

Reduced representation methods such as restriction site associated DNA sequencing (RAD-seq) [73] and Hybridization-based gene capture [64,74] significantly expand the gamut of available genetic data for chondrichthyan taxonomic descriptions and population studies. Subsampling of the genome by sequencing DNA fragments associated with selected restriction sites through RAD-seq [75] or by using hundreds or thousands of predesigned sequence probes to hybridize and capture genetic regions from multiple related species [64] provides access to numerous adaptive and neutral microsatellite and SNP loci for taxonomic and population studies.

Double digest RAD-seq (ddRAD-seq) was used to identify 8 novel microsatellite loci to assist molecular ecology research in the dusky shark (Carcharhinus melanopterus), an economically and recreationally important species [76]. Hybridization-based gene capture determined the evolutionary history of Carcharhinus melanopterus metapopulations by sampling many loci from few individuals [74]. Metapopulations exhibit greater resilience to changes in effective population size compared to unstructured populations [74]. Complete mitochondrial genomes obtained through gene capture were used to identify marine dispersal and transoceanic gene flow in river sharks, that were previously described as freshwater species [64]. Restriction enzymes and hybridization probes are selected to target homologous genetic regions in many closely related species and to sample large parts of the genome independent of amplification. However, these methods require extensive development and optimization of protocols for multiple species analysis and depend upon sequence homology, which could pose challenges for studying highly divergent species.

2b-RAD-seq uses IIb restriction enzymes to generate even-sized libraries followed by the selection of DNA fragments of interest using biotinylated adapters with affinity for the restriction enzyme. Selection of even-sized DNA fragments of interest reduces the library size and allows deeper coverage and higher accuracy. Manuzzi et al., 2019 [22] achieved high resolution in SNP analyses with 2b-RAD-seq, which led to the uncovering of previously undetected population structure in the small-spotted cat shark populations across part of its Northeast Atlantic range here.

\subsection{Genome Skimming: A Non-Targeted Approach to Sub-Sampling Chondrichthyan Genomes}

Target loci development for multiple species and associated selection biases can be avoided and access to several genetic regions across the mitochondrial and nuclear genomes can be obtained through whole genome shotgun sequencing (WGS). WGS involves fragmenting genomic DNA into short fragments and sequencing an entire large genome or multiple small genomes using high throughput sequencing. WGS offers the largest coverage of all genetic loci without selection or amplification biases and is an ideal choice for exploratory studies, especially those involving non-model and divergent species. WGS can overcome most limitations of the barcoding assay and can be used for a wide variety 
of applications, including species biodiversity assessments, phylogenomic and population genetic studies. However, the use of WGS is restricted due to its requirement for high sequencing depth in order to sequence all relevant loci. This requirement for high depth and coverage makes it cost-intensive, especially in case of chondrichthyan genomes which are 1-7 gigabases in length $[14,18,70,71]$.

Genome skimming, which allows deep sequencing of high copy number genomic DNA fractions, is a viable alternative to WGS for chondrichthyan biodiversity assessments. Genome skimming allows deep sequencing of nuclear ribosomal DNA (rDNA), repeat regions of nuclear DNA such as microsatellite DNA and mitochondrial DNA fractions (Figure 1), which are typically used for species identification, resolution of genetic variation in species distributed across geographic barriers, and resolution of evolutionary relationships between species and species groups, for individual, kinship, and migration studies [28]. Deep sequencing of these loci could effectively subsample the genome for regions of interest without the need for amplification or pre-selection of target loci. This approach eliminates amplification or selection biases while targeting genomic regions in multiple related or divergent species.

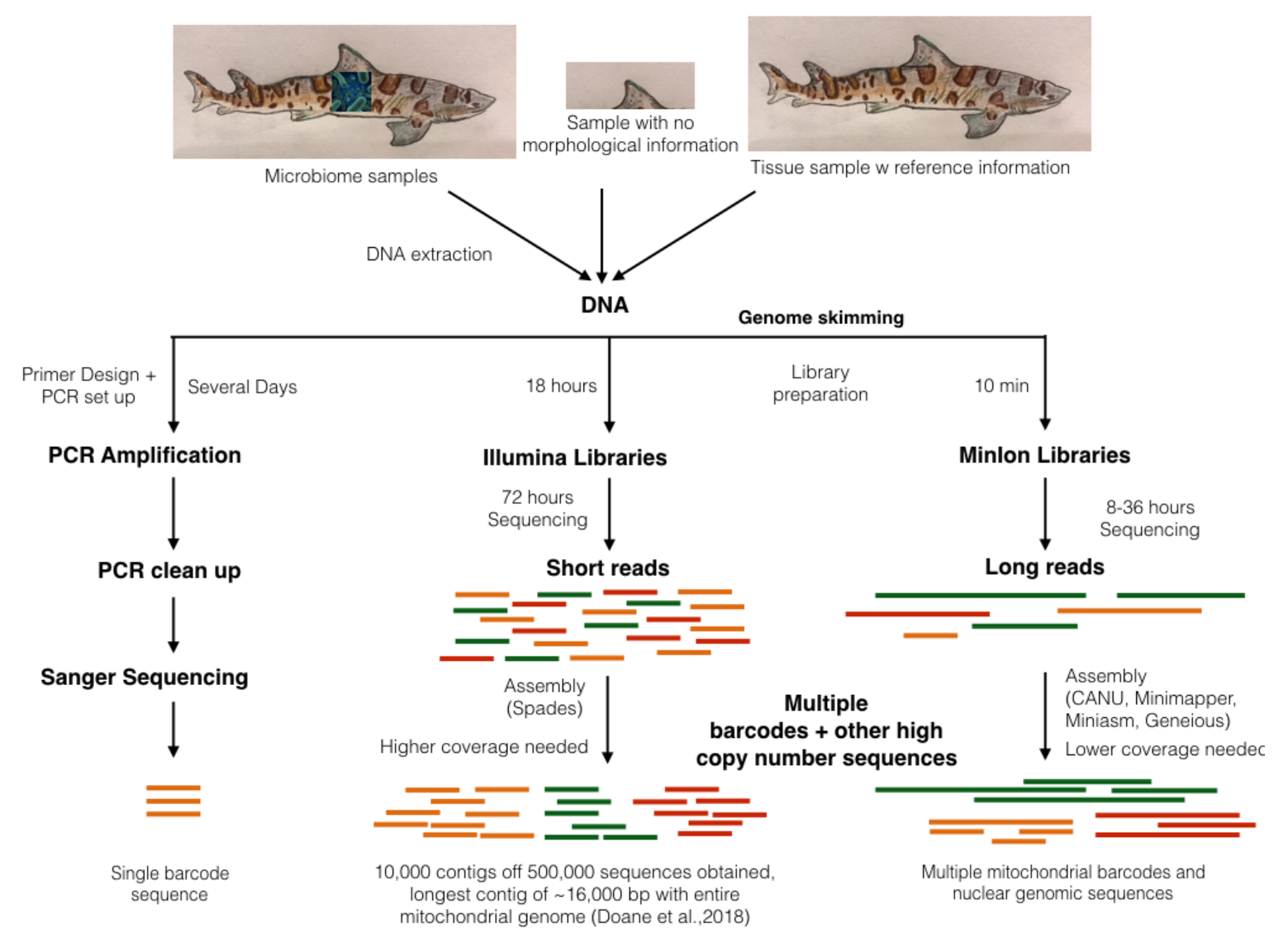

Figure 1. Comparison of sequence data obtained with Genome skimming and PCR-based approaches. PCR based targeted approaches take several days to optimize PCR amplification, run the PCR, clean up the product and obtain sequence information of a single genetic locus from chondrichthyan DNA. Genome skimming with Oxford Nanopore Technologies (ONT) or Illumina sequencing platforms takes anywhere from $10 \mathrm{~min}$ to $18 \mathrm{~h}$, respectively, for library preparation using genomic DNA. Sequencing the prepared samples takes between $8 \mathrm{~h}$ to $72 \mathrm{~h}$ respectively, depending on the platform used and sequencing depth required. At the end of a genome skimming run one has access to multiple barcodes, microsatellites, SNPs, as well as other high and low copy number regions of the genome. Genome skimming can allow accurate taxonomic assessments from dismembered chondrichthyan specimens through extensive genomic data sets, as opposed to single locus information from PCR based approaches. 
Johri et al., 2019 [42] conducted 'Genome skimming' analyses on the $C$. falciformis genome, the first and only study employing the method in Chondrichthyes. This method allowed access to previously unexplored parts of the silky shark nuclear genome which encode developmental and immune function proteins, among others. The entire mitochondrial genome of $C$. falciformis was also obtained which provided a correct version of the mitogenome, compared to the previously published genome which had a 1000 bp insertion from errors introduced during sequencing or analyses [77]. Last, access to the nuclear and mitochondrial genomes also allowed assignment of accurate taxonomic identity to a market specimen based on multigenic analyses and provided strong evidence for inclusion of the blue shark (P. Glauca) in the Carcharhinus genus.

Genome skimming has similarly allowed remarkable expansion in phylogenetic markers used for molecular systematics, and biodiversity studies of many other animal and plant species [10,78]. Previously unexplored mitochondrial genetic loci from species in the Annelidae family were isolated for phylogenomic studies and provided resolution of phylogenetic positions for the Glyceridae family, which was previously not possible using morphological analyses [10]. The authors defined three separate clades within the family, which comprised all but one species, identified a nested position for Hemipodia simplex within the Glycera genus as opposed to a monophyletic relationship with other genera described previously [10]. The presence of cryptic species was identified within G. americana, G. tridactyla, and G. capitata. Last, by comparing data obtained from sequencing at different coverage depths, they found that sequencing coverage could be reduced significantly without losing data for important high copy number regions of the genome [10].

Genome skimming increases access to low copy genes that underlie morphological diversification. To describe the value in genome skimming, we use a plant species example in which the evolution of floral symmetry associated genes was characterized across 21 plant species [78]. Protein coding and upstream and downstream regulatory sequences for four CYCLOIDEA (CYC) genes from 21 non-model species were obtained [78], and each of the four genes and regulatory regions were aligned across species to understand changes in protein sequence and expression that explain diversification in floral symmetry patterns across species [78].

Genome skimming enables large fractions of the mitochondrial and nuclear genomes to be explored with more efficiency compared to targeted sequencing approaches. While the initial investment is higher, the data returns are greater (Figure 1). Genome skimming in Chondrichthyes would allow access to multiple commonly used barcode sequences and additional genomic regions to be accessible through low-overall coverage and low-cost sequencing runs. Commonly used barcode sequences could be isolated without a priori knowledge of species sequences and without an amplification bias. Genome skimming could significantly enhance access to prehistoric or museum specimens which typically have highly degraded DNA and PCR amplification of candidate genes is challenging, due to the absence or low quality of primer binding regions. These data could facilitate seamless species identification, phylogenetic, kinship, biogeographic and population genetic studies by compensating for low DNA quality with multiple nuclear and mitochondrial genetic loci.

A significant drawback of genome skimming is that whether coverage of essential genomic regions such as mitochondrial barcodes will be achieved using genome skimming cannot be predicted. However, as seen in Section 4.3 below, the mitochondria is readily obtained from non-targeted sequencing and increasing sequencing depth will further improve coverage.

\section{Microbiome as a Health Monitoring Tool for Chondrichthyes}

The increase in the occurrence of anthropogenic and natural disturbances in the environment makes it imperative to monitor wildlife-environment interactions to understand the effect of environmental stressors on the health of wildlife populations. Monitoring of wildlife populations with respect to environmental disturbances is thus integral to conservation and management of marine species. Monitoring of marine wildlife populations is invasive and resource-intensive, creates inherent risks to wildlife populations and is challenging due to limited accessibility in the marine environment. 
Altogether, these factors have led to limited success in the conservation of marine species and habitats. Emerging techniques reliant on high-throughput sequencing technologies, such as metagenomics provide less invasive alternatives for health monitoring of marine organisms and the detection of anthropogenic or natural threats in the environment.

All terrestrial and marine organisms share the environment with an enormous diversity of microorganisms, including protists, archaea, bacteria, viruses, and fungi. The use of genomic and metagenomic methods has enabled the description of the vast diversity of microbes distributed across environments $[4,79-83]$ and of the microbes that are closely associated with animals, termed the microbiome [7,79,84-90]. Importance of the microbiome in organismal health is being realized [91], with increased understanding of the role microbes play in overall functioning of the host through development and support of immune function [92,93], phenotypic expression [94], reproduction [95], nutrient acquisition [93], response to pollutants [96,97] and response to habitat degradation [98].

Microbiomes of marine organisms are often species specific [88], distinct from the water column in which the organisms inhabit [99], and play important symbiotic roles [100]. For marine organisms, some of these microbiome members originate and are selected from the surrounding seawater [101], while others are inherited and passed on through generations from the host [102]. Interactions between the host and environment in the establishment and maintenance of the microbiome are currently being modeled $[103,104]$. Tracking the fluctuation of microbiome composition across healthy and diseased individuals has led to the dysbiosis hypothesis [105], which suggests that disturbances in the environment or host nutrition and health increase fluctuations in microbial composition, and destabilize it $[6,106]$. The emergent composition and properties of the microbiome often correlate with the host exhibiting specific disease phenotypes $[107,108]$.

Fundamental understanding of microbial diversity has also expanded dramatically and extended to some non-model organisms $[98,109,110]$. Yet, there remains a paucity of microbiome studies in marine organisms [110], and this significantly restricts our understanding of marine ecosystem health. We highlight advances made in the field of chondrichthyan microbial ecology and discuss implications of these studies in chondrichthyan ecology, conservation and management.

\subsection{S rRNA and Shot-Gun Metagenomics to Study Chondrichthyan Microbiomes}

To study microbiomes, microbial community samples are collected en masse from the target environment, and the DNA sequence from a random subset is obtained using two approaches, $16 \mathrm{~S}$ rRNA amplicon sequencing or whole genome shot-gun metagenomics. Amplicon sequencing targets one or more loci within the $16 \mathrm{~S}$ rRNA gene and provides a taxonomic composition of the microbiome. With shot-gun metagenomics, random sequences across multiple genomic regions are obtained [4,82], and these sequences provide a census of both the taxonomic groups and functional genes present within each taxon of the microbiome (Figure 2). The latter is a more comprehensive assessment of host microbiomes and an effective monitoring tool to assess changes in host microbiome composition and function associated with environmental disturbances.

There have been only a few investigations of chondrichthyan microbiomes [99,111-116], but these few studies have vastly increased our understanding of chondrichthyan ecology and interactions with the environment. Two of these studies were conducted using whole shot-gun metagenomics to describe microbial taxa and function on the skin of thresher sharks, Alopias vulpinus [99,116], while the rest used 16S rRNA amplicon sequencing to describe microbial diversity [111-113]. The skin microbiome was the focus of two chondrichthyan microbiome studies [99,112], first because shark skins being covered in dermal denticles have unusual characteristics and provide an interesting environment for microbiome studies, and second because skin microbiome samples can be collected non-invasively. Skin microbiomes of sharks can be collected either by capture and release of sharks or by free-diving with sharks which do not pose a safety concern (e.g., Whale sharks) [99,117]. 


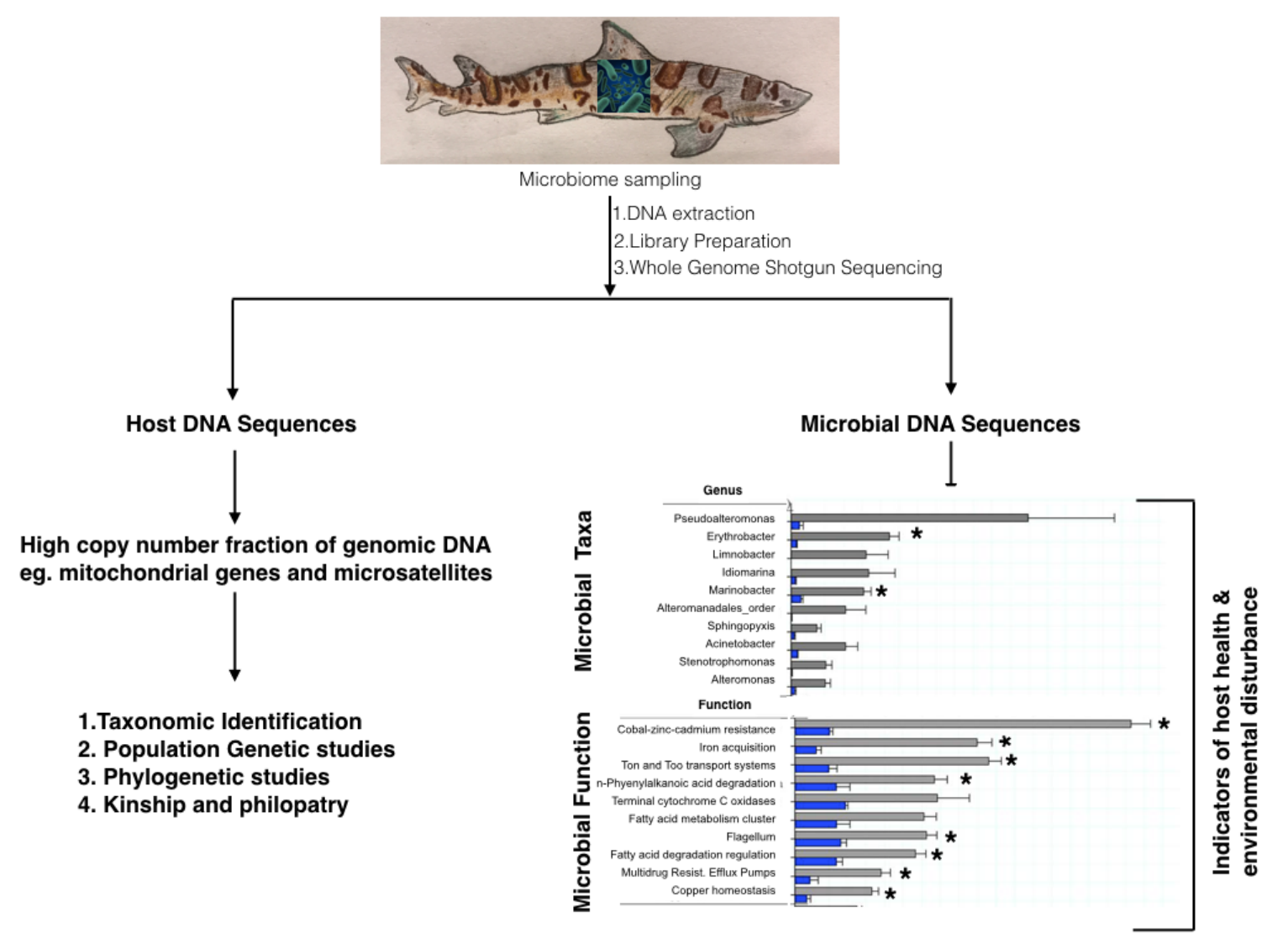

Figure 2. Microbiomes facilitate understanding of host genomics, host-microbe interactions and host physiology. Microbiome analyses using whole genome shot-gun metagenomics allows access to genomic information along with an understanding of microbial taxonomic and functional diversity. Host genomes thus obtained provide a non-invasive means for taxonomic identification, phylogenetic analyses, population genetic and kinship studies. A description of microbial taxa and function, facilitate understanding of host physiology and health and provide a non-invasive monitoring tool for longitudinal studies in chondrichthyan populations. The graphs above, adapted from [99] Doane et al., 2017 provide a description of microbial taxa and function associated with thresher sharks (grey) and sea water (blue).

Analyses of the thresher shark skin microbiome [99] and that of the gut microbiome of five pelagic sharks $[113,115]$ identified a high proportion of unclassified operational taxonomic units (OTUs), suggesting that shark microbiomes are novel. However, in all cases the microbiome was dominated by proteobacteria and the shark skin microbiome had several genera that were distinctive from the water column such as Pseudoalteromonas, Erythrobacter, Marinobacter, and Idiomarina, whereas the water was dominated by Roseobacter, Ruegeria and Synechococcus (Figure 2) [99]. Analysis of the cow-nose rays from an aquarium setting revealed a distinct microbiome from the surrounding water column and identified similarities and differences in microbial diversity and core composition between the dorsal and ventral surfaces of the rays, with Burkholderiales, Flavobacteriales, and Pseudomonadales being present on the dorsal side and Vibrionales on the ventral side [112].

Both the skin and gut microbiomes of sharks and rays differed from those of teleost fish and cetaceans found in similar environments [99,109,111,112]. Structural characteristics of the skin microbiome of sharks differed compared to host species with a mucus lining such that sharks have a low beta-diversity in their microbial composition [99]. However, these data may be skewed due to the high percentage of novel species in shark microbiomes and warrant further investigation with more shark species. In addition, the shark and ray skin microbiomes had low beta diversity, which means that each individual organism shared many of the same bacterial genera, unlike algae in which 
each individual host had fewer shared bacterial taxa [99,112]. A sequence level similarity analysis was conducted on the shark skin microbiome to account for unclassified sequences, and an approximate $60 \%$ similarity was seen in sharks of the same species compared to $\sim 20 \%$ similarity among algae, and $5 \%$ between water column metagenomes [99]. It is possible that this high rate of similarity between microbiomes of individuals from the same species is linked to the unusual surface characteristics of the chondrichthyan skin and may explain the lack of known diseases and faster wound healing in sharks $[15,16]$. However, these hypotheses remain to be tested.

Genomic techniques can be used to forensically identify the cause of death of wild organisms. In 2017, hundreds of leopard sharks washed up on beaches in California and whole shotgun metagenomics was used to identify the potential pathogens [116]. Moribund and healthy sharks were collected and subcutaneous fluid surrounding the endolymphatic ducts, inner ear perilymph, and cerebrospinal fluid were collected, and DNA extracted for targeted and whole shotgun metagenomics. These areas of the shark were targeted because the sharks were showing signs of abnormal swimming behavior and disorientation, suggesting a central nervous system problem. The metagenomic analysis identified a ciliate as the most likely pathogen. The presence of the ciliate was confirmed with targeted PCR. The microbiome of the sharks was not measured prior to the die-off and thus is it unknown whether there were other factors affecting the sharks. Conducting routine metagenomic analysis of shark skin could be used to monitor the health of shark populations in the wild.

Shotgun metagenomics identifies the genes and metabolic functions that the microbes possess. Distinguishing characteristics were also observed in the nutrient acquisition pathways of chondrichthyan microbiomes and the water column. Sequences encoding genes in Ton/tol pathway were six-fold higher in the A. vulpinus microbiome compared to coral reefs $\mathrm{M}$. In coral reefs, the proportion of Ton/tol encoding sequences has been positively correlated to high phosphate levels in the host [118], suggesting the role of microbiome functions in the acquisition of limiting nutrients. The thresher shark microbiome had a high representation of sequences encoding anti-microbial pathways such as the n-phenylalkanoic acid degradation pathway $[99,119]$, suggesting anti-microbial abilities of the shark microbiome. These data suggest the range of unique abilities of the shark skin microbiome along with the occurrence of many potentially important host-microbiome interactions with significant health impacts and call for further investigations.

In general, Chondrichthyes are interesting model organisms for understanding host-microbiome interactions and microbiome inheritance. The amount of vertical versus environmental influence in microbiome establishment could be determined by comparing Chondrichthyes with viviparous vs. oviparous modes of reproduction. Second, the effect of dermal denticles, as a physical barrier in Chondrichthyes, compared with a chemical or mucus barrier seen in the teleost, to microbial recruitment is a particularly interesting area of research. Understanding these interactions could lead to new frontiers in antimicrobial research and drug discovery, in addition to a renewed understanding of host-microbe interactions.

\subsection{Microbiomes in a Changing Environment}

The microbiome is reciprocally regulated by the host and environmental factors. Diet and environment of the host impact the gut microbiome [120]. For wild animals, shifts in diet occur with habitat degradation and exposure to environmental pollutants, both of which have profound impacts on the animal's microbiome. An inferior microbiome composition and function occurred in howler monkeys living in degraded habitats compared to those living in pristine habitats [98]. Shifts in mouse gut microbiome and resultant acute increase in inflammation and metabolic disorders occur as a result of persistent organic pollutant (POP) exposure [97]. The microbiome is thus a bioindicator of environmental and nutritional stress to the host.

Microbiomes are specific to species [99,109,112] and environments [4] and change with disturbances in the environment or host health $[6,98,105,106]$. Thus, longitudinal studies monitoring the shifts in the microbiome of individuals or populations of a species could allow microbiomes 
to be used as a measure of individual or population health. Kearns et al., 2017 [112] monitored cow-nose rays to determine changes in the microbiome and effects on the animals' health after contact with humans. However, no changes in the ray microbiome were observed, suggesting that the unusual characteristics of chondrichthyan skin may provide a unique way of recruiting and maintaining the ray microbiome, and this native microbiome in turn may support the chondrichthyan immune system, just like in humans. Shot-gun metagenomic studies of thresher sharks revealed the presence of several overrepresented and interesting functional groups in categories such as, (i) virulence, disease and defense; (ii) motility and chemotaxis; (iii) iron acquisition and (iv) membrane transport [99]. A ten-fold higher abundance of heavy metal metabolizing genes was also identified in the thresher shark microbiomes compared to the water column and other organisms in the environment (Figure 2) [99], suggesting heavy metal contamination and bioaccumulation in sharks or a natural occurrence of these genes in the shark microbiome. Iron acquisition genes were also significantly overrepresented in the thresher shark microbiome [99] and microbes with the ability to acquire iron more efficiently are suited to compete in the microbiome arena, suggesting high levels of interactions between microbial community members. Evidently, these data call for further research to improve our understanding of microbiomes associated with natural chondrichthyan populations and shifts in the microbiome from environmental disturbances. Longitudinal studies of chondrichthyan populations could allow the use of microbiomes as a non-invasive monitoring tool to detect environmental and physiological disturbances.

Microbiomes as a health monitoring tool can easily be deployed alongside other monitoring of marine organisms, such as tagging studies, fisheries surveys or baited remote underwater video cameras (BRUVS), and we have shown that it can provide a wealth of information about the microbial community, genomics of the host species, health status and, by investigating the functional genes, the presence of heavy metal and other contaminants in the marine environment.

\subsection{Metagenomics to Obtain Host Genomes}

Microbiome collection from host species and from environments, frequently leads to a collection of host DNA (Doane et al., 2018) [117]. Since the whole genome shot-gun sequencing does not rely on targeted sequencing of microbial DNA, it allows the host mitochondrial DNA to be sequenced along with microbial DNA (Figure 2). Thus, shotgun genomics offers a non-invasive alternative to access host genomic data in parallel with microbial genomics. In addition to describing the genomics of the host, shotgun metagenomics offers the advantage of re-constructing metagenome-associated genomes (MAGs) [121-123]. To construct these genomes, sequence reads from multiple metagenomes are pooled, assembled and binned using various characteristics, such as sequence distribution [121,122] and frequency of K-mers [122,124]. This process describes novel microbes that are found associated with many marine organisms $[99,100]$.

The entire mitochondrial genomic sequence of thresher sharks was isolated in a study that was exploring shark skin microbiomes [117]. A few shark skin cells or perhaps free DNA were isolated during shark skin microbiome collection and this was followed by DNA extraction and 'shallow sequencing' of the shark genomes. Sequencing of the shark genome was conducted along with microbial metagenomes using a single run of the Ion torrent platform, which had approximately 12 metagenomic samples being sequenced in parallel. Of these, six metagenomic samples from the sharks, which consisted of 380,000 to 1.3 million sequences, most of which were microbial, but had sufficient sequencing to obtain the mitochondrial genome of the shark [117]. The sequencing of thresher sharks' mitochondrial DNA clarified the placement of the Lamniformes family with the Carcharhiniformes family, rather than with the Orectolobiformes family [117]. Sequencing the mitochondria showed that $A$. vulpinus and A. pelagicus underwent the most recent divergence, with A. superciliosus forming an outgroup [117].

Microbial and eukaryotic genomes have been similarly isolated, sequenced on the Illumina MiSeq and analyzed by undergraduate students in an ecological metagenomics class at San Diego 
State University [1]. For many of these samples organismal genomes were obtained from a single microbial sample per host species, while in others microbial genomes were cross assembled from several samples of the same species. Cross assembly is conducted by combining all samples from the same organism or environment for subsequent assembly of the organism's genome [122,124]. Metagenomes were assembled using Spades [125] or Geneious ${ }^{\circledR}$ 11.1.2 [126] and the largest contig of $\sim 16,000$ bp was aligned to reference genomes using Blastn ${ }^{\circledR}$ [127]. Undergraduate students were able to assemble the eukaryotic mitochondria and microbial genomes within a lab session, suggesting that the bioinformatics are becoming relatively straightforward to complete, making these methods amenable for capacity building among researchers with varying skill levels [1].

\section{Environmental DNA (eDNA)-To Monitor the Elusive Ocean Predator}

An extension from microbial metagenomics, which focused on collecting an environmental sample and sequencing the bacterial and archaeal organisms that are present, is environmental DNA (eDNA), where eukaryote specific primers are used to determine the eukaryotes present in an environment $[128,129]$. eDNA is DNA that is left in the environment as the organisms swim past, and includes cells sloughing off the skin, hair follicles, organismal products including mucus, scales, feces etc [130]. The DNA remains viable for a limited period and can be collected to identify organisms that are present within an environment. Eukaryotic eDNA is generally in low concentration requiring a primer and amplification approach. The primers are either universal, mostly the CO1, $12 \mathrm{~S}$ rRNA and $18 \mathrm{~S}$ rRNA to survey eukaryotic members across multiple trophic levels [30,131]. A specific primer could be added to the general primers to identify the presence of a single species or group like sharks $[132,133]$. eDNA metabarcoding is used for cataloging biodiversity at multiple trophic levels in a location to establish a baseline against which future sampling can be compared to monitor community changes. The greatest advantage of eDNA is its non-invasiveness and non-fishing requirement, making eDNA analysis important for biodiversity assessments of endangered organisms, such as Chondrichthyes.

eDNA investigations of sharks have used a single primer to target a single species as using a primer to target multiple species has been problematic. The problems have occurred due to several groups, like the Carcharhinids being polyphylogenetic and therefore, the separation between species with a single primer is difficult [30]. However, the Shark COI-MINIR $127 \mathrm{bp}$ shark specific region of the CO1 barcode [134] was combined with two fish-specific primers to describe the species diversity of sharks in the Caribbean and Pacific oceans. The analysis revealed a higher diversity of sharks in the Pacific compared to the Caribbean, with higher biodiversity identified in locations further from human populations. Locations such as Jamaica and Belize were depauperate, and the Bahamas showed higher diversity, suggestive of more effective management at the later location. Similarly, in the Pacific, more distant locations, such as Chesterfield Reef, in the Pacific, had the highest diversity of species. The number of shark-specific reads ranges from 0 to 2500 per sample suggesting a wide variation in the number of sharks present, however, estimation of organism abundance from sequence number is not precise. The survey however, describes the distribution of elasmobranchs in large oceanographic regions, where observing large, fast-moving elusive animals is difficult through traditional survey techniques.

eDNA surveys have detected sharks where traditional methods have failed. In a survey of the New Caledonian archipelago, eDNA detected $44 \%$ more shark species than traditional underwater visual censuses and baited videos, despite two orders of magnitude less sampling effort [135]. The eDNA analysis of the New Caledonian region identified the presence of previously unobserved shark species in human-impacted areas. This exciting result suggests that while many sharks have been removed, there was greater prevalence than expected, which indicated that large-scale eDNA assessments are required to improve monitoring of threatened and elusive megafauna.

The non-targeted eDNA surveys require sequencing of the sample and comparison to the database. This process is somewhat expensive and in many samples the target organisms, i.e., sharks may not 
be present, and therefore, a large number of sequences are obtained that belong to other eukaryote groups that are not used in the analysis. For example, out of 2.9 million sequences, only 21, 542 sequences were identified as a species of shark [133]. Therefore, for a target organism a specific primer followed by a digital droplet PCR (ddPCR) can be used to identify the presence or absence of a shark's DNA in a sample. ddPCR uses florescence to identify and quantify the presence of a specific sequence in a sample, without sequencing. The ddPRC method could be used to identify the presence of potentially hazardous sharks, e.g., white sharks, in coastal areas during events such as surfing contests. This approach was tested using a $163 \mathrm{bp}$ fragment of the white shark (Carcharodon carcharias) mitochondrial Cytochrome oxidase B gene [133]. The marker was detected using only $250 \mathrm{~mL}$ of water. The white sharks were detected in the locations where two tag sharks were identified from and there was no detection in two adjacent areas, presumably because the sharks were not present at the time of sampling. No detection occurred in negative controls. This marker provides a fisheries independent measure of the presence of sharks and could monitor the presence of white sharks and inform management for purposes of conservation and public safety. Over the last few decades white sharks have received significant attention with respect to conservation management [136], including being CITES listed, and protected in Australia, New Zealand and California USA. There is potential for an increase in abundance and interactions with humans [137], therefore, easily identifying the presence of this species at local beaches could alleviate public safety concerns.

Environmental DNA analysis of whale shark aggregations confirmed that eDNA provides useful genetic diversity data as similar mitochondrial haplotype frequencies were identified in the eDNA as that recovered from tissues [132]. Therefore, eDNA could be used for population level analysis. In addition, multiple marker genes were used to describe the presence of both whale sharks and their potential prey [132]. eDNA therefore can provide information on both the population level genetics and species diversity.

eDNA lends itself to the collection by non-scientists and could encourage citizen scientists. For example, Johri et al., (unpublished) asked the fisherman to collect water samples at set distances from shore as they conducted daily fishing expeditions. The analysis used shark specific primers and identified that shark populations started to increase at increasing distance from the shore. Given a large number of people accessing the coastal environment, encouraging the boating community to collect water samples may provide a large body of data to understand species distribution and identify habitats used by these elusive marine predators.

\section{Taking Genomics to the Field}

A crucial aim in molecular ecology, wildlife forensics, and biodiversity studies is to sequence as close to the sampling site as possible. Whole genome sequencing or genome skimming provide a marked relief in burden to ecologists and conservation biologists working with non-model species as these approaches eliminate the need for $a$ priori sequence information for non-model species, and do not require PCR optimization, PCR amplification and post-PCR processing. They only require gDNA extraction, library preparation and sequencing. WGS and genome skimming have been made even more accessible by the latest advent in high-throughput sequencing technologies from Oxford Nanopore Technologies (ONT) of hand-held, scalable and portable sequencing devices [138]. ONT's MinION device requires library preparation of sample DNA for $10 \mathrm{~min}$, sequencing for 8-48 h and offers read lengths of tens of kilobases, limited only by the quality of genomic DNA used for sequencing. The device has a low capital cost compared to Illumina sequencers, and allows sequence analyses in real-time with a simplified sequence acquisition platform. Large read lengths available through MinION sequencing are already improving genome sequence assemblies for small to large size genomes [139-142], while the portable and fast sequencing features have increased the ease of use for molecular genetics in ecological [8] and clinical [143-145] applications respectively. In addition to whole genome sequencing, the real time sequence analyses platform of the MinION device allows selective sequencing using applications like ‘Read Until' [146] in which sequence identity is determined 
from the first few sequenced bases and the user decides whether to keep sequencing the sample at hand or to terminate and sequence the next sample.

Long read sequences obtained from the MinION have been used to assist genome assemblies for small [140-142], medium [139] and large genomes up to $3 \mathrm{~Gb}$ in size [147]. Assemblies can be conducted independently with the MinION sequencer or by combining long reads from the MinION sequencer with short read sequences from Illumina sequencers $[139,140]$. Long read sequences offer the advantage of genome assembly with low coverage data sets [148]. MinION assemblies by themselves provided accurate genome assemblies, detection of structural variants and SNPs and assessed genome evolution for the Drosophila melanogaster, Caenorhabditis elegans and human genomes [141,142,147]. Thus, for ecological and forensic studies of Chondrichthyes, MinION sequencers could be leveraged for genome wide analyses of chondrichthyan genomes which have sizes in the 1-6.7 GB range [14,18,70,71]. Alternatively, genome skimming of chondrichthyan genomes on the MinION device could enable quick access to high copy number fractions of the genome and allow taxonomic identification for ecological and forensic application [42]. Detailed analyses and assembly of genomic data from the sequencer post field work could enable broader biogeographic and population genetic studies of the chondrichthyan species under consideration, significantly expand the scope of Chondrichthyan biodiversity studies globally and assist conservation management of this species in areas with urgent need, but minimal infrastructure and resources.

Depending on expertise available in the field either complex bioinformatics assembly programs such as CANU [149] could be used for assembly of long read sequences or sequence assembly could be done using standalone software such as Geneious ${ }^{\circledR}$ 11.1.2 [126] or analyses pipelines developed and used by $[1,42,150]$. Taxonomic identification using high copy number regions such as mitochondrial barcodes could be achieved in field research projects by Blast alignment [127] and phylogenetic analyses using a curated database of chondrichthyan sequences from Genbank on a laptop computer. Thus, multiple genetic loci from chondrichthyan specimens could be isolated for ecological and forensic studies using genome sequencing and analyses on portable sequencers such as the MinION. These research goals could be achieved irrespective of research location and laboratory infrastructure and facilities, due to the portable nature of this technology. However, use of the MinION sequencer remains expensive compared to PCR analyses and Illumina sequencing of individual samples. In addition, although long read sequences from the MinION compensate for low coverage of large genomes such as those of Chondrichthyes, whether coverage of essential genomic regions such as mitochondrial barcodes will be achieved on a given MinION sequencing run cannot be predicted. Thus, even as the portability of the sequencer makes it more accessible to researchers with few resources, the cost of sequencing with MinION may limit its adoption in some areas of need, at least in the short term.

\section{Conclusions}

In summary, comprehensive elasmobranch biodiversity assessments require access to several mitochondrial and nuclear genetic loci. Current elasmobranch research trends involve targeted approaches to access one or a few loci within the mitochondrial or nuclear genomes based on the study requirements, and significant effort is invested in the development of these assays. A targeted approach has global implications for chondrichthyan research such that it limits research to well established laboratories only, limits the mainstream use of chondrichthyan genomic databases and above all, severely limits the scope of chondrichthyan research.

However, a small but increasing number of researchers are incorporating genomics to use multiple genetic markers in their studies for inferring biogeography and population structure of Chondrichthyes. This approach overcomes limitations of amplification biases resulting from use of single loci and allows acquisition of genetic data from previously unevaluated and potentially new species, thus significantly reducing data deficiency in chondrichthyes. Multiple molecular markers allow information to be obtained along a 'time continuum' based on the evolutionary genetic diversity of each marker and provide a window into the complete population history of a species. 
Next-generation sequencing technologies are increasing accessibility to chondrichthyan genomes and making genome wide assessments more common place in research.

Genomic and metagenomic data from Chondrichthyes at the individual or population level, serve as a 'lifetime tag' for these animals and could allow non-invasive longitudinal studies of the species' migration patterns, philopatry and health. These data provide essential baseline information about population structure which is essential to effective conservation and management of these species. In addition, with more data from around the world, larger ecological questions can be asked, such as describing the differential biogeography patterns in microbial taxa and functional genes of chondrichthyan populations worldwide. Above all, genomic studies of chondrichthyan populations are key to understanding species distributions and population structures which are crucial to efficient conservation and management of this species group. Genomic studies of chondrichthyes thus hold enormous potential to increase the depth and breadth of our understanding of chondrichthyan ecology, health, behavior and conservation.

In the current article, we have provided a comprehensive review of genomic and metagenomic tools to facilitate genomic studies of Chondrichthyes and provide innovative tools for forensic and ecological investigations. We expect that the methods discussed here will receive acceptance by academic researchers and conservation managers alike and that they will be used to bridge the existing data gaps that constrain conservation and management of chondrichthyan populations.

Author Contributions: S.J. contributed to the concept, writing and editing all sections of the manuscript, M.P.D. contributed to writing, L.A. contributed to figure design, and E.A.D. contributed to the concept, writing and editing of the manuscript.

Funding: This research was funded by S. Lo and B. Billings, the NSF Division of Undergraduate Education grant \# 1323809 and NSF Division of Molecular and Cellular Science grant \# 1330800.

Acknowledgments: We acknowledge support for this work from the Society for Conservation Biology-Marine Section. We are immensely thankful to all Dinsdale laboratory members for help with editing this manuscript. We are also thankful for the many conversations with members of fishing communities in India which provided us with a focus and understanding of the needs of chondrichthyan fisheries and conservation on the ground. Last, we are immensely thankful to Dr. Nicholas Dulvy and Dr. Naveen Namboothri, for the many conversations which assisted in setting up the framework for this manuscript.

Conflicts of Interest: The authors declare no conflict of interest.

\section{References}

1. Edwards, R.A.; Haggerty, J.M.; Cassman, N.; Busch, J.C.; Aguinaldo, K.; Chinta, S.; Vaughn, M.H.; Morey, R.; Harkins, T.T.; Teiling, C.; et al. Microbes, metagenomes and marine mammals: enabling the next generation of scientist to enter the genomic era. BMC Genom. 2013, 14, 600. [CrossRef] [PubMed]

2. Ellegren, H. Genome sequencing and population genomics in non-model organisms. Trends Ecol. Evol. 2014, 29, 51-63. [CrossRef] [PubMed]

3. Guyer, M.S.; Collins, F.S. The Human Genome Project and the future of medicine. Am. J. Dis. Child. 1993, 147, 1145-1152. [CrossRef] [PubMed]

4. Haggerty, J.M.; Dinsdale, E.A. Distinct biogeographical patterns of marine bacterial taxonomy and functional genes. Glob. Ecol. Biogeogr. 2017, 26, 177-190. [CrossRef]

5. Ma, D.; Liu, F. Genome Editing and Its Applications in Model Organisms. Geno. Proteomics Bioinform. 2015, 13, 336-344. [CrossRef]

6. Minich, J.J.; Morris, M.M.; Brown, M.; Doane, M.; Edwards, M.S.; Michael, T.P.; Dinsdale, E.A. Elevated temperature drives kelp microbiome dysbiosis, while elevated carbon dioxide induces water microbiome disruption. PLOS ONE 2018, 13, e0192772. [CrossRef]

7. Turnbaugh, P.J.; Ley, R.E.; Hamady, M.; Fraser-Liggett, C.; Knight, R.; Gordon, J.I. The human microbiome project: exploring the microbial part of ourselves in a changing world. Nature 2007, 449, 804-810. [CrossRef]

8. Menegon, M.; Cantaloni, C.; Rodriguez-Prieto, A.; Centomo, C.; Abdelfattah, A.; Rossato, M.; Bernardi, M.; Xumerle, L.; Loader, S.; Delledonne, M. On site DNA barcoding by nanopore sequencing. PLoS ONE 2017, 12, e0184741. [CrossRef] 
9. Morris, M.M.; Haggerty, J.M.; Papudeshi, B.N.; Vega, A.A.; Edwards, M.S.; Dinsdale, E.A. Nearshore Pelagic Microbial Community Abundance Affects Recruitment Success of Giant Kelp, Macrocystis pyrifera. Front. Microbiol. 2016, 7, 1800. [CrossRef]

10. Richter, S.; Schwarz, F.; Hering, L.; Böggemann, M.; Bleidorn, C. The Utility of Genome Skimming for Phylogenomic Analyses as Demonstrated for Glycerid Relationships (Annelida, Glyceridae). Genome Biol. Evol. 2015, 7, 3443-3462. [CrossRef] [PubMed]

11. Ripma, L.A.; Simpson, M.G.; Hasenstab-Lehman, K. Geneious! Simplified genome skimming methods for phylogenetic systematic studies: A case study in Oreocarya (Boraginaceae). Appl. Plant Sci. 2014, 2, 1400062. [CrossRef] [PubMed]

12. Kriwet, J.; Witzmann, F.; Klug, S.; Heidtke, U.H.J. First direct evidence of a vertebrate three-level trophic chain in the fossil record. Proc. R. Soc. B Biol. Sci. 2008, 275, 181-186. [CrossRef]

13. Stein, R.W.; Mull, C.G.; Kuhn, T.S.; Aschliman, N.C.; Davidson, L.N.K.; Joy, J.B.; Smith, G.J.; Dulvy, N.K.; Mooers, A.O. Global priorities for conserving the evolutionary history of sharks, rays and chimaeras. Nat. Ecol. Evol. 2018, 2, 288-298. [CrossRef]

14. Marra, N.J.; Stanhope, M.J.; Jue, N.K.; Wang, M.; Sun, Q.; Bitar, P.P.; Richards, V.P.; Komissarov, A.; Rayko, M.; Kliver, S.; et al. White shark genome reveals ancient elasmobranch adaptations associated with wound healing and the maintenance of genome stability. Proc. Natl. Acad. Sci. USA 2019, 116, 4446-4455. [CrossRef] [PubMed]

15. Reif, W.-E. Wound healing in Sharks: Form and arrangement of repair scales. Zoomorphologie 1978, 90, 101-111. [CrossRef]

16. Chin, A.; Mourier, J.; Rummer, J.L. Blacktip reef sharks (Carcharhinus melanopterus) show high capacity for wound healing and recovery following injury. Conserv. Physiol. 2015, 3. [CrossRef] [PubMed]

17. Domingues, R.R.; Hilsdorf, A.W.S.; Gadig, O.B.F. The importance of considering genetic diversity in shark and ray conservation policies. Conserv. Genet. 2018, 19, 501-525. [CrossRef]

18. Venkatesh, B.; Lee, A.P.; Ravi, V.; Maurya, A.K.; Lian, M.M.; Swann, J.B.; Ohta, Y.; Flajnik, M.F.; Sutoh, Y.; Kasahara, M.; et al. Elephant shark genome provides unique insights into gnathostome evolution. Nature 2014, 505, 174-179. [CrossRef]

19. Dulvy, N.K.; Fowler, S.L.; Musick, J.A.; Cavanagh, R.D.; Kyne, P.M.; Harrison, L.R.; Carlson, J.K.; Davidson, L.N.; Fordham, S.V.; Francis, M.P.; et al. Extinction risk and conservation of the world's sharks and rays. eLife 2014, 3, e00590. [CrossRef]

20. García, V.B.; Lucifora, L.O.; Myers, R.A. The importance of habitat and life history to extinction risk in sharks, skates, rays and chimaeras. Proc. R. Soc. Lond. B Biol. Sci. 2008, 275, 83-89. [CrossRef]

21. Taguchi, M.; King, J.R.; Wetklo, M.; Withler, R.E.; Yokawa, K. Population Genetic Structure and Demographic History of Pacific Blue Sharks (Prionace glauca) Inferred from Mitochondrial DNA Analysis-Dimensions. Available online: https:/ /app.dimensions.ai/details/publication/pub.1035226050 (accessed on 24 September 2018).

22. Manuzzi, A.; Zane, L.; Muñoz-Merida, A.; Griffiths, A.M.; Veríssimo, A. Population genomics and phylogeography of a benthic coastal shark (Scyliorhinus canicula) using 2b-RAD single nucleotide polymorphisms. Biol. J. Linn. Soc. 2019, 126, 289-303. [CrossRef]

23. Gallagher, A.J.; Hammerschlag, N.; Shiffman, D.S.; Giery, S.T. Evolved for Extinction: The Cost and Conservation Implications of Specialization in Hammerhead Sharks. BioScience 2014, 64, 619-624. [CrossRef]

24. Stevens, J. The effects of fishing on sharks, rays, and chimaeras (chondrichthyans), and the implications for marine ecosystems. ICES J. Mar. Sci. 2000, 57, 476-494. [CrossRef]

25. Bernatchez, L.; Wellenreuther, M.; Araneda, C.; Ashton, D.T.; Barth, J.M.I.; Beacham, T.D.; Maes, G.E.; Martinsohn, J.T.; Miller, K.M.; Naish, K.A.; et al. Harnessing the Power of Genomics to Secure the Future of Seafood. Trends Ecol. Evol. 2017, 32, 665-680. [CrossRef]

26. Carvalho, G.R.; Hauser, L.; Martinsohn, J.; Naish, K. Fish, genes and genomes: contributions to ecology, evolution and management. J. Fish Biol. 2016, 89, 2471-2478. [CrossRef]

27. Ungerer, M.C.; Johnson, L.C.; Herman, M.A. Ecological genomics: Understanding gene and genome function in the natural environment. Heredity 2008, 100, 178-183. [CrossRef]

28. Dudgeon, C.L.; Blower, D.C.; Broderick, D.; Giles, J.L.; Holmes, B.J.; Kashiwagi, T.; Krück, N.C.; Morgan, J.A.T.; Tillett, B.J.; Ovenden, J.R. A review of the application of molecular genetics for fisheries management and conservation of sharks and rays. J. Fish Biol. 2012, 80, 1789-1843. [CrossRef] 
29. Hebert, P.D.N.; Cywinska, A.; Ball, S.L.; de Waard, J.R. Biological identifications through DNA barcodes. Proc. R. Soc. B Biol. Sci. 2003, 270, 313-321. [CrossRef] [PubMed]

30. Bakker, J.; Wangensteen, O.S.; Chapman, D.D.; Boussarie, G.; Buddo, D.; Guttridge, T.L.; Hertler, H.; Mouillot, D.; Vigliola, L.; Mariani, S. Environmental DNA reveals tropical shark diversity in contrasting levels of anthropogenic impact. Sci. Rep. 2017, 7, 16886. [CrossRef] [PubMed]

31. Bineesh, K.K.; Gopalakrishnan, A.; Akhilesh, K.V.; Sajeela, K.A.; Abdussamad, E.M.; Pillai, N.G.K.; Basheer, V.S.; Jena, J.K.; Ward, R.D. DNA barcoding reveals species composition of sharks and rays in the Indian commercial fishery. Mitochondrial DNA Part DNA Mapp. Seq. Anal. 2016, 28, 458-472. [CrossRef]

32. Chuang, P.-S.; Hung, T.-C.; Chang, H.-A.; Huang, C.-K.; Shiao, J.-C. The Species and Origin of Shark Fins in Taiwan's Fishing Ports, Markets, and Customs Detention: A DNA Barcoding Analysis. PLoS ONE 2016, 11, e0147290. [CrossRef] [PubMed]

33. Steinke, D.; Bernard, A.M.; Horn, R.L.; Hilton, P.; Hanner, R.; Shivji, M.S. DNA analysis of traded shark fins and mobulid gill plates reveals a high proportion of species of conservation concern. Sci. Rep. 2017, 7, 9505. [CrossRef]

34. Henderson, A.C.; Reeve, A.J.; Jabado, R.W.; Naylor, G.J.P. Taxonomic assessment of sharks, rays and guitarfishes (Chondrichthyes: Elasmobranchii) from south-eastern Arabia, using the NADH dehydrogenase subunit 2 (NADH2) gene. Zool. J. Linn. Soc. 2016, 176, 399-442. [CrossRef]

35. Naylor, G.J.P.; Caira, J.N.; Jensen, K.; Rosana, K.A.M.; White, W.T.; Last, P.R. A DNA sequence-based approach to the identification of shark and ray species and its implications for global elasmobranch diversity and parasitology. (Bulletin of the American Museum of Natural History, no. 367). DNA Identif. Sharks Rays 2012. Available online: http:/ / digitallibrary.amnh.org/handle/2246/6183 (accessed on 18 March 2019).

36. Boomer, J.J.; Peddemors, V.; Stow, A.J. Genetic data show that Carcharhinus tilstoni is not confined to the tropics, highlighting the importance of a multifaceted approach to species identification. J. Fish Biol. 2010, 77, 1165-1172. [CrossRef]

37. Morgan, J.A.T.; Harry, A.V.; Welch, D.J.; Street, R.; White, J.; Geraghty, P.T.; Macbeth, W.G.; Tobin, A.; Simpfendorfer, C.A.; Ovenden, J.R. Detection of interspecies hybridisation in Chondrichthyes: hybrids and hybrid offspring between Australian (Carcharhinus tilstoni) and common (C. limbatus) blacktip shark found in an Australian fishery. Conserv. Genet. 2012, 13, 455-463. [CrossRef]

38. Rodrigues-Filho, L.F.d.S.; da Rocha, T.C.; do Rêgo, P.S.; Schneider, H.; Sampaio, I.; Vallinoto, M. Identification and phylogenetic inferences on stocks of sharks affected by the fishing industry off the Northern coast of Brazil. Genet. Mol. Biol. 2009, 32, 405-413. [CrossRef] [PubMed]

39. Pinhal, D.; Shivji, M.S.; Nachtigall, P.G.; Chapman, D.D.; Martins, C. A streamlined DNA tool for global identification of heavily exploited coastal shark species (genus Rhizoprionodon). PLoS ONE 2012, 7, e34797. [CrossRef] [PubMed]

40. Moore, A.B.M.; White, W.T.; Ward, R.D.; Naylor, G.J.P.; Peirce, R. Rediscovery and redescription of the smoothtooth blacktip shark, Carcharhinus leiodon (Carcharhinidae), from Kuwait, with notes on its possible conservation status. Mar. Freshw. Res. 2011, 62, 528. [CrossRef]

41. Ward, R.D.; Zemlak, T.S.; Innes, B.H.; Last, P.R.; Hebert, P.D. DNA barcoding Australia's fish species. Philos. Trans. R. Soc. B Biol. Sci. 2005, 360, 1847-1857. [CrossRef]

42. Johri, S.; Solanki, J.; Cantu, V.A.; Fellows, S.R.; Edwards, R.A.; Moreno, I.; Vyas, A.; Dinsdale, E.A. 'Genome skimming' with the MinION hand-held sequencer identifies CITES-listed shark species in India's exports market. Sci. Rep. 2019, 9, 4476. [CrossRef] [PubMed]

43. Naylor, G.J.; Ryburn, J.A.; Fedrigo, O.; Lopez, J.A. Phylogenetic relationships among the major lineages of modern elasmobranchs. Reprod. Biol. Phylogeny 2005, 3, 25.

44. Haasl, R.J.; Payseur, B.A. Microsatellites as Targets of Natural Selection. Mol. Biol. Evol. 2013, 30, $285-298$. [CrossRef]

45. Hoelzel, A.R.; Shivji, M.S.; Magnussen, J.; Francis, M.P. Low worldwide genetic diversity in the basking shark (Cetorhinus maximus). Biol. Lett. 2006, 2, 639-642. [CrossRef] [PubMed]

46. Castro, A.L.F. Use of molecular tools on surveys of genetic variation and population structure in three species of sharks. Ph.D. Thesis, University of South Florida, Tampa, FL, USA, 2009. Available online: https: / / scholarcommons.usf.edu/etd/1893 (accessed on 18 October 2018).

47. Karl, S.A.; Castro, A.L.F.; Garla, R.C. Population genetics of the nurse shark (Ginglymostoma cirratum) in the western. Atlantic. Mar. Biol. 2012, 159, 489-498. [CrossRef] 
48. Pardini, A.T.; Jones, C.; Noble, L.; Kreiser, B.; Malcolm, H.; Bruce, B.D.; Stevens, J.D.; Cliff, G.; Scholl, M.; Francis, M.; et al. Sex-biased dispersal of great white sharks - In some respects, these sharks behave more like whales and dolphins than other fish. Nature 2001, 412, 139-140. [CrossRef]

49. Gubili, C.; Bilgin, R.; Kalkan, E.; Karhan, U.; Jones, C.S.; Sims, D.W.; Kabasakal, H.; Martin, A.; Noble, L.R. Antipodean white sharks on a Mediterranean walkabout? Historical dispersal leads to genetic discontinuity and an endangered anomalous population. Proc. R. Soc. Lond. B Biol. Sci. 2011, 278, 1679-1686. [CrossRef]

50. Keeney, D.B.; Heist, E.J. Worldwide phylogeography of the blacktip shark (Carcharhinus limbatus) inferred from mitochondrial DNA reveals isolation of western Atlantic populations coupled with recent Pacific dispersal. Mol. Ecol. 2006, 15, 3669-3679. [CrossRef] [PubMed]

51. Karl, S.; Castro, A.L.F.; López, J.; Charvet, P.; Burgess, G. Phylogeography and conservation of the bull shark (Carcharhinus leucas) inferred from mitochondrial and microsatellite DNA. Conserv. Genet. 2011, 12, 371-382. [CrossRef]

52. Tillett, B.J.; Meekan, M.G.; Broderick, D.; Field, I.C.; Cliff, G.; Ovenden, J.R. Pleistocene isolation, secondary introgression and restricted contemporary gene flow in the pig-eye shark, Carcharhinus amboinensis across northern Australia. Conserv. Genet. 2012, 13, 99-115. [CrossRef]

53. Ovenden, J.R.; Morgan, J.A.T.; Street, R.; Tobin, A.; Simpfendorfer, C.; Macbeth, W.; Welch, D. Negligible evidence for regional genetic population structure for two shark species Rhizoprionodon acutus (Rüppell, 1837) and Sphyrna lewini (Griffith \& Smith, 1834) with contrasting biology. Mar. Biol. 2011, 158, 1497-1509.

54. Veríssimo, A.; McDowell, J.R.; Graves, J.E. Population structure of a deep-water squaloid shark, the Portuguese dogfish (Centroscymnus coelolepis). ICES J. Mar. Sci. 2011, 68, 555-563. [CrossRef]

55. Veríssimo, A.; McDowell, J.R.; Graves, J.E. Global population structure of the spiny dogfish Squalus acanthias, a temperate shark with an antitropical distribution. Mol. Ecol. 2010, 19, 1651-1662. [CrossRef]

56. Bester-van der Merwe, A.E.; Bitalo, D.; Cuevas, J.M.; Ovenden, J.; Hernández, S.; da Silva, C.; McCord, M.; Roodt-Wilding, R. Population genetics of Southern Hemisphere tope shark (Galeorhinus galeus): Intercontinental divergence and constrained gene flow at different geographical scales. PLOS ONE 2017, 12, e0184481. [CrossRef]

57. Crandall, K.; Bininda-Emonds, O.; Mace, G.; Wayne, R.K. Considering evolutionary process in conservation biology. Trends Ecol. Evol. 2000, 15, 290-295. [CrossRef]

58. Frankel, O.H. Genetic conservation: our evolutionary responsibility. Genetics 1974, 78, 53-65. [PubMed]

59. Ryder, O. Species conservation and systematics: the dilemma of subspecies. Trends Ecol. Evol. 1986, 1, 9-10.

60. Brumfield, R.T.; Beerli, P.; Nickerson, D.A.; Edwards, S.V. The utility of single nucleotide polymorphisms in inferences of population history. Trends Ecol. Evol. 2003, 18, 249-256. [CrossRef]

61. Pirog, A.; Blaison, A.; Jaquemet, S.; Soria, M.; Magalon, H. Isolation and characterization of 20 microsatellite markers from Carcharhinus leucas (bull shark) and cross-amplification in Galeocerdo cuvier (tiger shark), Carcharhinus obscurus (dusky shark) and Carcharhinus plumbeus (sandbar shark). Conserv. Genet. Resour. 2015, 7, 121-124. [CrossRef]

62. Mendes, N.J.; Cruz, V.P.; Mendonça, F.F.; Pardo, B.G.; Coelho, R.; Ashikaga, F.Y.; Camargo, S.M.; Martínez, P.; Oliveira, C.; Santos, M.N.; et al. Microsatellite loci in the oceanic whitetip shark and cross-species amplification using pyrosequencing technology. Conserv. Genet. Resour. 2015, 7, 585-589. [CrossRef]

63. Mendes, N.J.; Cruz, V.P.; Ashikaga, F.Y.; Camargo, S.M.; Oliveira, C.; Piercy, A.N.; Burgess, G.H.; Coelho, R.; Santos, M.N.; Mendonça, F.F.; et al. Microsatellite loci in the tiger shark and cross-species amplification using pyrosequencing technology. PeerJ 2016, 4, e2205. [CrossRef] [PubMed]

64. Li, C.; Hofreiter, M.; Straube, N.; Corrigan, S.; Naylor, G.J.P. Capturing protein-coding genes across highly divergent species. BioTechniques 2013, 54, 321-326. [CrossRef]

65. Momigliano, P.; Harcourt, R.; Robbins, W.D.; Jaiteh, V.; Mahardika, G.N.; Sembiring, A.; Stow, A. Genetic structure and signatures of selection in grey reef sharks (Carcharhinus amblyrhynchos). Heredity 2017, 119, 142-153. [CrossRef]

66. Pazmiño, D.A.; Maes, G.E.; Simpfendorfer, C.A.; Salinas-de-León, P.; Herwerden, L. Van Genome-wide SNPs reveal low effective population size within confined management units of the highly vagile Galapagos shark (Carcharhinus galapagensis). Conserv. Genet. 2017, 18, 1151-1163. [CrossRef]

67. Planes, S.; Fauvelot, C. Isolation by distance and vicariance drive genetic structure of a coral reef fish in the Pacific Ocean. Evol. Int. J. Org. Evol. 2002, 56, 378-399. [CrossRef] 
68. Pazmiño, D.; Maes, G.; Green, M.; Simpfendorfer, C.; Hoyos, M.; Duffy, C.; Meyer, C.; Kerwath, S.; Salinas-de-Leon, P.; Herwerden, L. Strong trans-Pacific break and local conservation units in the Galapagos shark (Carcharhinus galapagensis) revealed by genome-wide cytonuclear markers. Heredity 2018, 120. [CrossRef] [PubMed]

69. Portnoy, D.; Puritz, J.; Hollenbeck, C.M.; Gelsleichter, J.; Chapman, D.; Gold, J. Selection and sex-biased dispersal in a coastal shark: The influence of philopatry on adaptive variation. Mol. Ecol. 2015, $24,5885$. [CrossRef] [PubMed]

70. Read, T.D.; Petit, R.A.; Joseph, S.J.; Alam, M.T.; Weil, M.R.; Ahmad, M.; Bhimani, R.; Vuong, J.S.; Haase, C.P.; Webb, D.H.; et al. Draft sequencing and assembly of the genome of the world's largest fish, the whale shark: Rhincodon typus Smith 1828. BMC Genom. 2017, 18, 532.

71. Hara, Y.; Yamaguchi, K.; Onimaru, K.; Kadota, M.; Koyanagi, M.; Keeley, S.D.; Tatsumi, K.; Tanaka, K.; Motone, F.; Kageyama, Y.; et al. Shark genomes provide insights into elasmobranch evolution and the origin of vertebrates. Nat. Ecol. Evol. 2018, 2, 1761. [CrossRef]

72. Dooley, H.; Flajnik, M.F. Shark immunity bites back: Affinity maturation and memory response in the nurse shark, Ginglymostoma cirratum. Eur. J. Immunol. 2015, 35, 936-945. [CrossRef]

73. Bernal, M.A.; Sinai, N.L.; Rocha, C.; Gaither, M.R.; Dunker, F.; Rocha, L.A. Long-term sperm storage in the brownbanded bamboo shark Chiloscyllium punctatum. J. Fish Biol. 2014, 86, 1171-1176. [CrossRef] [PubMed]

74. Delser, P.M.; Corrigan, S.; Hale, M.; Li, C.; Veuille, M.; Planes, S.; Naylor, G.; Mona, S. Population genomics of $C$. melanopterus using target gene capture data: demographic inferences and conservation perspectives. Sci. Rep. 2016, 6, 33753. [CrossRef]

75. Etter, P.D.; Bassham, S.; Hohenlohe, P.A.; Johnson, E.A.; Cresko, W.A. SNP discovery and genotyping for evolutionary genetics using RAD sequencing. Methods Mol. Biol. 2011, 772, 157-178. [PubMed]

76. Maduna, S.N.; Rossouw, C.; Slabbert, R.; Wintner, S.P.; da Silva, C.; Bester-van der Merwe, A.E. New polymorphic microsatellite loci revealed for the dusky shark Carcharhinus obscurus through Ion Proton double-digest RAD sequencing. Mol. Biol. Rep. 2018. [CrossRef]

77. Galván-Tirado, C.; Hinojosa-Alvarez, S.; Diaz-Jaimes, P.; Marcet-Houben, M.; García-De-León, F.J. The complete mitochondrial DNA of the silky shark (Carcharhinus falciformis). Mitochondrial DNA Part A Mapp. Seq. Anal. 2016, 27, 157-158. [CrossRef]

78. Berger, B.A.; Han, J.; Sessa, E.B.; Gardner, A.G.; Shepherd, K.A.; Ricigliano, V.A.; Jabaily, R.S.; Howarth, D.G. The Unexpected Depths of Genome-Skimming Data: A Case Study Examining Goodeniaceae Floral Symmetry Genes. Appl. Plant. Sci. 2017, 5, 1700042. [CrossRef]

79. Beattie, G.A. Metabolic coupling on roots. Nat. Microbiol. 2018, 3, 396-397. [CrossRef]

80. Cassman, N.; Prieto-Davó, A.; Walsh, K.; Silva, G.G.Z.; Angly, F.; Akhter, S.; Barott, K.; Busch, J.; McDole, T.; Haggerty, J.M.; et al. Oxygen minimum zones harbour novel viral communities with low diversity. Environ. Microbiol. 2012, 14, 3043-3065. [CrossRef] [PubMed]

81. Jeffries, T.C.; Seymour, J.R.; Gilbert, J.A.; Dinsdale, E.A.; Newton, K.; Leterme, S.S.C.; Roudnew, B.; Smith, R.J.; Seuront, L.; Mitchell, J.G. Substrate Type Determines Metagenomic Profiles from Diverse Chemical Habitats. PLOS ONE 2011, 6, e25173. [CrossRef]

82. Dinsdale, E.A.; Edwards, R.A.; Hall, D.; Angly, F.; Breitbart, M.; Brulc, J.M.; Furlan, M.; Desnues, C.; Haynes, M.; Li, L.; et al. Functional metagenomic profiling of nine biomes. Nature 2008, 452, 629-632. [CrossRef]

83. Walsh, K.; Haggerty, J.M.; Doane, M.P.; Hansen, J.J.; Morris, M.M.; Moreira, A.P.B.; de Oliveira, L.; Leomil, L.; Garcia, G.D.; Thompson, F.; et al. Aura-biomes are present in the water layer above coral reef benthic macro-organisms. PeerJ 2017, 5, e3666. [CrossRef] [PubMed]

84. Burke, C.; Steinberg, P.; Rusch, D.; Kjelleberg, S.; Thomas, T. Bacterial community assembly based on functional genes rather than species. Proc. Natl. Acad. Sci. USA 2011, 108, 14288-14293. [CrossRef] [PubMed]

85. Fan, L.; Reynolds, D.; Liu, M.; Stark, M.; Kjelleberg, S.; Webster, N.S.; Thomas, T. Functional equivalence and evolutionary convergence in complex communities of microbial sponge symbionts. Proc. Natl. Acad. Sci. USA 2012, 109, E1878-E1887. [CrossRef] [PubMed]

86. Larsen, A.; Tao, Z.; Bullard, S.A.; Arias, C.R. Diversity of the skin microbiota of fishes: evidence for host species specificity. FEMS Microbiol. Ecol. 2013, 85, 483-494. [CrossRef] [PubMed] 
87. McKenzie, V.J.; Bowers, R.M.; Fierer, N.; Knight, R.; Lauber, C.L. Co-habiting amphibian species harbor unique skin bacterial communities in wild populations. ISME J. 2012, 6, 588-596. [CrossRef] [PubMed]

88. Rohwer, F.; Seguritan, V.; Azam, F.; Knowlton, N. Diversity and distribution of coral-associated bacteria. Mar. Ecol. Progr. Ser. 2002, 243, 1-10. [CrossRef]

89. Sison-Mangus, M.P.; Jiang, S.; Kudela, R.M.; Mehic, S. Phytoplankton-Associated Bacterial Community Composition and Succession during Toxic Diatom Bloom and Non-Bloom Events. Front. Microbiol. $2016,7$. [CrossRef]

90. Sison-Mangus, M.P.; Jiang, S.; Tran, K.N.; Kudela, R.M. Host-specific adaptation governs the interaction of the marine diatom, Pseudo-nitzschia and their microbiota. ISME J. 2014, 8, 63-76. [CrossRef]

91. Consortium, T.H.M.P.; Huttenhower, C.; Gevers, D.; Knight, R.; Abubucker, S.; Badger, J.H.; Chinwalla, A.T.; Creasy, H.H.; Earl, A.M.; FitzGerald, M.G.; et al. Structure, function and diversity of the healthy human microbiome. Nature 2012, 486, 207-214.

92. Hooper, L.V.; Littman, D.R.; Macpherson, A.J. Interactions between the microbiota and the immune system. Science 2012, 336, 1268-1273. [CrossRef]

93. Kau, A.L.; Ahern, P.P.; Griffin, N.W.; Goodman, A.L.; Gordon, J.I. Human nutrition, the gut microbiome and the immune system. Nature 2011, 474, 327-336. [CrossRef]

94. Joint, I.; Tait, K.; Callow, M.E.; Callow, J.A.; Milton, D.; Williams, P.; Cámara, M. Cell-to-Cell Communication Across the Prokaryote-Eukaryote Boundary. Science 2002, 298, 1207. [CrossRef]

95. Fox, C.; Eichelberger, K. Maternal microbiome and pregnancy outcomes. Fertil. Steril. 2015, 104, 1358-1363. [CrossRef]

96. Busch, J.; Nascimento, J.R.; Magalhães, A.C.R.; Dutilh, B.E.; Dinsdale, E. Copper tolerance and distribution of epibiotic bacteria associated with giant kelp Macrocystis pyrifera in southern California. Ecotoxicology 2015, 24, 1131-1140. [CrossRef] [PubMed]

97. Zhang, L.; Nichols, R.G.; Correll, J.; Murray, I.A.; Tanaka, N.; Smith, P.B.; Hubbard, T.D.; Sebastian, A.; Albert, I.; Hatzakis, E.; et al. Persistent Organic Pollutants Modify Gut Microbiota-Host Metabolic Homeostasis in Mice Through Aryl Hydrocarbon Receptor Activation. Environ. Health Perspect. 2015, 123, 679-688. [CrossRef]

98. Amato, K.R.; Yeoman, C.J.; Kent, A.; Righini, N.; Carbonero, F.; Estrada, A.; Gaskins, H.R.; Stumpf, R.M.; Yildirim, S.; Torralba, M.; et al. Habitat degradation impacts black howler monkey (Alouatta pigra) gastrointestinal microbiomes. ISME J. 2013, 7, 1344-1353. [CrossRef] [PubMed]

99. Doane, M.P.; Haggerty, J.M.; Kacev, D.; Papudeshi, B.; Dinsdale, E.A. The skin microbiome of the common thresher shark (Alopias vulpinus) has low taxonomic and gene function $\beta$-diversity. Environ. Microbiol. Rep. 2017, 9, 357-373. [CrossRef]

100. Apprill, A.; Miller, C.A.; Moore, M.J.; Durban, J.W.; Fearnbach, H.; Barrett-Lennard, L.G. Extensive Core Microbiome in Drone-Captured Whale Blow Supports a Framework for Health Monitoring. mSystems 2017, 2, e00119-17. [CrossRef]

101. Nussbaumer, A.D.; Fisher, C.R.; Bright, M. Horizontal endosymbiont transmission in hydrothermal vent tubeworms. Nature 2006, 441, 345-348. [CrossRef] [PubMed]

102. Sharp, K.H.; Eam, B.; Faulkner, D.J.; Haygood, M.G. Vertical Transmission of Diverse Microbes in the Tropical Sponge Corticium sp. Appl. Environ. Microbiol. 2007, 73, 622-629.

103. Zeng, Q.; Wu, S.; Sukumaran, J.; Rodrigo, A. Models of microbiome evolution incorporating host and microbial selection. Microbiome 2017, 5, 127. [CrossRef] [PubMed]

104. Zeng, Q.; Rodrigo, A. Neutral models of short-term microbiome dynamics with host subpopulation structure and migration limitation. Microbiome 2018, 6, 80. [CrossRef] [PubMed]

105. Egan, S.; Gardiner, M. Microbial Dysbiosis: Rethinking Disease in Marine Ecosystems. Front. Microbiol. 2016, 7, 991. [CrossRef]

106. Cavalcanti, G.S.; Shukla, P.; Morris, M.; Ribeiro, B.; Foley, M.; Doane, M.P.; Thompson, C.C.; Edwards, M.S.; Dinsdale, E.A.; Thompson, F.L. Rhodoliths holobionts in a changing ocean: host-microbes interactions mediate coralline algae resilience under ocean acidification. BMC Genom. 2018, 19, 701. [CrossRef]

107. Janssens, Y.; Nielandt, J.; Bronselaer, A.; Debunne, N.; Verbeke, F.; Wynendaele, E.; Van Immerseel, F.; Vandewynckel, Y.-P.; De Tré, G.; De Spiegeleer, B. Disbiome database: linking the microbiome to disease. BMC Microbiol. 2018, 18, 50. [CrossRef] [PubMed] 
108. Liang, D.; Leung, R.K.-K.; Guan, W.; Au, W.W. Involvement of gut microbiome in human health and disease: Brief overview, knowledge gaps and research opportunities. Gut Pathog. 2018, 10. [CrossRef] [PubMed]

109. Apprill, A.; Robbins, J.; Eren, A.M.; Pack, A.A.; Reveillaud, J.; Mattila, D.; Moore, M.; Niemeyer, M.; Moore, K.M.T.; Mincer, T.J. Humpback Whale Populations Share a Core Skin Bacterial Community: Towards a Health Index for Marine Mammals? PLoS ONE 2014, 9, e90785. [CrossRef] [PubMed]

110. Colston, T.; Jackson, C. Invited Review: Microbiome Evolution Along Divergent Branches of the Vertebrate Tree of Life: What's Known and Unknown. Mol. Ecol. 2016, 25. [CrossRef]

111. Givens, C.E.; Ransom, B.; Bano, N.; Hollibaugh, J.T. Comparison of the gut microbiomes of 12 bony fish and 3 shark species. Mar. Ecol. Prog. Ser. 2015, 518, 209-223. [CrossRef]

112. Kearns, P.J.; Bowen, J.L.; Tlusty, M.F. The skin microbiome of cow-nose rays (Rhinoptera bonasus) in an aquarium touch-tank exhibit. Zoo Biol. 2017, 36, 226-230. [CrossRef] [PubMed]

113. Sherrill-Mix, S.; McCormick, K.; Lauder, A.; Bailey, A.; Zimmerman, L.; Li, Y.; Django, J.-B.N.; Bertolani, P.; Colin, C.; Hart, J.A.; et al. Allometry and Ecology of the Bilaterian Gut Microbiome. mBio 2018, 9, e00319-18. [CrossRef]

114. Barbato, M.; Kovacs, T.; Coleman, M.A.; Broadhurst, M.K.; Bruyn, M. De Metabarcoding for stomach-content analyses of Pygmy devil ray (Mobula kuhlii cf. eregoodootenkee): Comparing tissue and ethanol preservative-derived. DNA. Ecol. Evol. 2019, 9, 2678-2687. [PubMed]

115. Johny, T.K.; Saidumohamed, B.E.; Sasidharan, R.S.; Bhat, S.G. Metabarcoding data of bacterial diversity of the deep sea shark, Centroscyllium fabricii. Data Brief 2018, 21, 1029-1032. [CrossRef] [PubMed]

116. Retallack, H.; Okihiro, M.S.; Britton, E.; Van Sommeran, S.; DeRisi, J.L. Metagenomic Next-Generation Sequencing Reveals Miamiensis avidus (Ciliophora: Scuticociliatida) in the 2017 Epizootic of Leopard Sharks (Triakis semifasciata) in San Francisco Bay, California, USA. J. Wildl. Dis. 2018, 55. [CrossRef] [PubMed]

117. Doane, M.P.; Kacev, D.; Harrington, S.; Levi, K.; Pande, D.; Vega, A.; Dinsdale, E.A. Mitochondrial recovery from shotgun metagenome sequencing enabling phylogenetic analysis of the common thresher shark (Alopias vulpinus). Meta Gene 2018, 15, 10-15. [CrossRef]

118. Kelly, L.W.; Williams, G.J.; Barott, K.L.; Carlson, C.A.; Dinsdale, E.A.; Edwards, R.A.; Haas, A.F.; Haynes, M.; Lim, Y.W.; McDole, T.; et al. Local genomic adaptation of coral reef-associated microbiomes to gradients of natural variability and anthropogenic stressors. Proc. Natl. Acad. Sci. USA 2014, 111, 10227-10232. [CrossRef] [PubMed]

119. Bowman, J.P. Bioactive compound synthetic capacity and ecological significance of marine bacterial genus pseudoalteromonas. Mar. Drugs 2007, 5, 220-241. [CrossRef] [PubMed]

120. Muegge, B.D.; Kuczynski, J.; Knights, D.; Clemente, J.C.; González, A.; Fontana, L.; Henrissat, B.; Knight, R.; Gordon, J.I. Diet drives convergence in gut microbiome functions across mammalian phylogeny and within humans. Science 2011, 332, 970-974. [CrossRef] [PubMed]

121. Dutilh, B.E.; Schmieder, R.; Nulton, J.; Felts, B.; Salamon, P.; Edwards, R.A.; Mokili, J.L. Reference-independent comparative metagenomics using cross-assembly: crAss. Bioinformatics 2012, 28, 3225-3231. [CrossRef]

122. Papudeshi, B.; Haggerty, J.M.; Doane, M.; Morris, M.M.; Walsh, K.; Beattie, D.T.; Pande, D.; Zaeri, P.; Silva, G.G.Z.; Thompson, F.; et al. Optimizing and evaluating the reconstruction of Metagenome-assembled microbial genomes. BMC Genom. 2017, 18, 915. [CrossRef]

123. Parks, D.H.; Rinke, C.; Chuvochina, M.; Chaumeil, P.-A.; Woodcroft, B.J.; Evans, P.N.; Hugenholtz, P.; Tyson, G.W. Recovery of nearly 8,000 metagenome-assembled genomes substantially expands the tree of life. Nature Microbiol. 2017, 2, 1533-1542. [CrossRef]

124. Alneberg, J.; Bjarnason, B.S.; de Bruijn, I.; Schirmer, M.; Quick, J.; Ijaz, U.Z.; Loman, N.J.; Andersson, A.F.; Quince, C. CONCOCT: Clustering cONtigs on COverage and ComposiTion. arXiv, 2013; arXiv:1312.4038. Available online: http:/ / arxiv.org/abs/1312.4038)(accessed on 27 July 2018).

125. Bankevich, A.; Nurk, S.; Antipov, D.; Gurevich, A.A.; Dvorkin, M.; Kulikov, A.S.; Lesin, V.M.; Nikolenko, S.I.; Pham, S.; Prjibelski, A.D.; et al. SPAdes: A New Genome Assembly Algorithm and Its Applications to Single-Cell Sequencing. J. Comput. Biol. 2012, 19, 455-477. [CrossRef]

126. Kearse, M.; Moir, R.; Wilson, A.; Stones-Havas, S.; Cheung, M.; Sturrock, S.; Buxton, S.; Cooper, A.; Markowitz, S.; Duran, C.; et al. Geneious Basic: an integrated and extendable desktop software platform for the organization and analysis of sequence data. Bioinformatics 2012, 28, 1647-1649. [CrossRef] 
127. NCBI Resource Coordinators Database Resources of the National Center for Biotechnology Information. Nucleic Acids Res. 2017, 45, D12-D17. [CrossRef] [PubMed]

128. Evans, N.T.; Li, Y.; Renshaw, M.A.; Olds, B.P.; Deiner, K.; Turner, C.R.; Jerde, C.L.; Lodge, D.M.; Lamberti, G.A.; Pfrender, M.E. Fish community assessment with eDNA metabarcoding: effects of sampling design and bioinformatic filtering. Can. J. Fish. Aquat. Sci. 2017, 74, 1362-1374. [CrossRef]

129. Stat, M.; John, J.; DiBattista, J.D.; Newman, S.J.; Bunce, M.; Harvey, E.S. Combined use of eDNA metabarcoding and video surveillance for the assessment of fish biodiversity: Fish Surveying. Conserv. Biol. 2019, 33, 196-205. [CrossRef] [PubMed]

130. Djurhuus, A.; Port, J.; Closek, C.J.; Yamahara, K.M.; Romero-Maraccini, O.; Walz, K.R.; Goldsmith, D.B.; Michisaki, R.; Breitbart, M.; Boehm, A.B.; et al. Evaluation of Filtration and DNA Extraction Methods for Environmental DNA Biodiversity Assessments across Multiple Trophic Levels. Front. Mar. Sci. 2017, 4. [CrossRef]

131. Andruszkiewicz, E.A.; Starks, H.A.; Chavez, F.P.; Sassoubre, L.M.; Block, B.A.; Boehm, A.B. Biomonitoring of marine vertebrates in Monterey Bay using eDNA metabarcoding. PLoS ONE 2017, 12, e0176343. [CrossRef] [PubMed]

132. Sigsgaard, E.E.; Nielsen, I.B.; Bach, S.S.; Lorenzen, E.D.; Robinson, D.P.; Knudsen, S.W.; Pedersen, M.W.; Jaidah, M.A.; Orlando, L.; Willerslev, E.; et al. Population characteristics of a large whale shark aggregation inferred from seawater environmental DNA. Nat. Ecol. Evol. 2016, 1, s41559-016. [CrossRef] [PubMed]

133. Lafferty, K.D.; Benesh, K.C.; Mahon, A.R.; Jerde, C.L.; Lowe, C.G. Detecting Southern California's White Sharks With Environmental DNA. Front. Mar. Sci. 2018, 5. [CrossRef]

134. Fields, A.T.; Abercrombie, D.L.; Eng, R.; Feldheim, K.; Chapman, D.D. A Novel Mini-DNA Barcoding Assay to Identify Processed Fins from Internationally Protected Shark Species. PLoS ONE 2015, 10, e0114844. [CrossRef]

135. Boussarie, G.; Bakker, J.; Wangensteen, O.S.; Mariani, S.; Bonnin, L.; Juhel, J.-B.; Kiszka, J.J.; Kulbicki, M.; Manel, S.; Robbins, W.D.; et al. Environmental DNA illuminates the dark diversity of sharks. Sci. Adv. 2018, 4, eaap9661. [CrossRef]

136. Dewar, H.; Eguchi, T.; Hyde, J.; Kinzey, D.; Kohin, S.; Moore, J.; Taylor, B.; Vetter, R. Status Review of the Northeastern Pacific Population of White Sharks (Carcharodon carcharias) under the Endangered Species Act. Available online: https:/ / swfsc.noaa.gov/publications/TM/SWFSC/NOAA-TM-NMFS-SWFSC-523.pdf (accessed on 23 March 2019).

137. Cape Cod's Gray Seal and White Shark Problem Is Anything but Black-and-White. Available online: https:/ / www.nrdc.org/onearth/cape-cods-gray-seal-and-white-shark-problem-anything-blackand-white (accessed on 18 March 2019).

138. Laver, T.; Harrison, J.; O’Neill, P.A.; Moore, K.; Farbos, A.; Paszkiewicz, K.; Studholme, D.J. Assessing the performance of the Oxford Nanopore Technologies MinION. Biomol. Detect. Quantif. 2015, 3, 1-8. [CrossRef]

139. Jansen, H.J.; Liem, M.; Jong-Raadsen, S.A.; Dufour, S.; Weltzien, F.-A.; Swinkels, W.; Koelewijn, A.; Palstra, A.P.; Pelster, B.; Spaink, H.P.; et al. Rapid de novo assembly of the European eel genome from nanopore sequencing reads. Sci. Rep. 2017, 7, 7213. [CrossRef] [PubMed]

140. Minei, R.; Hoshina, R.; Ogura, A. De novo assembly of middle-sized genome using MinION and Illumina sequencers. BMC Genom. 2018, 19, 700. [CrossRef] [PubMed]

141. Solares, E.A.; Chakraborty, M.; Miller, D.E.; Kalsow, S.; Hall, K.; Perera, A.G.; Emerson, J.J.; Hawley, R.S. Rapid Low-Cost Assembly of the Drosophila melanogaster Reference Genome Using Low-Coverage, Long-Read Sequencing. G3 Genes Genomes Genet. 2018, 8, 3143-3154. [CrossRef] [PubMed]

142. Tyson, J.R.; O’Neil, N.J.; Jain, M.; Olsen, H.E.; Hieter, P.; Snutch, T.P. MinION-based long-read sequencing and assembly extends the Caenorhabditis elegans reference genome. Genome Res. 2018, 28, 266-274. [CrossRef] [PubMed]

143. Greninger, A.L.; Naccache, S.N.; Federman, S.; Yu, G.; Mbala, P.; Bres, V.; Stryke, D.; Bouquet, J.; Somasekar, S.; Linnen, J.M.; et al. Rapid metagenomic identification of viral pathogens in clinical samples by real-time nanopore sequencing analysis. Genome Med. 2015, 7. [CrossRef]

144. Hoenen, T.; Groseth, A.; Rosenke, K.; Fischer, R.J.; Hoenen, A.; Judson, S.D.; Martellaro, C.; Falzarano, D.; Marzi, A.; Squires, R.B.; et al. Nanopore Sequencing as a Rapidly Deployable Ebola Outbreak Tool. Emerg. Infect. Dis. 2016, 22, 331-334. [CrossRef] 
145. Mataseje, L.F.; Abdesselam, K.; Vachon, J.; Mitchel, R.; Bryce, E.; Roscoe, D.; Boyd, D.A.; Embree, J.; Katz, K.; Kibsey, P.; et al. Results from the Canadian Nosocomial Infection Surveillance Program on Carbapenemase-Producing Enterobacteriaceae, 2010 to 2014. Antimicrob. Agents Chemother. 2016, 60, 6787-6794. [CrossRef] [PubMed]

146. Loose, M.; Malla, S.; Stout, M. Real-time selective sequencing using nanopore technology. Nat. Methods 2016, 13, 751-754. [CrossRef] [PubMed]

147. Jain, M.; Koren, S.; Miga, K.H.; Quick, J.; Rand, A.C.; Sasani, T.A.; Tyson, J.R.; Beggs, A.D.; Dilthey, A.T.; Fiddes, I.T.; et al. Nanopore sequencing and assembly of a human genome with ultra-long reads. Nat. Biotechnol. 2018, 36, 338-345. [CrossRef] [PubMed]

148. Sims, D.; Sudbery, I.; Ilott, N.E.; Heger, A.; Ponting, C.P. Sequencing depth and coverage: key considerations in genomic analyses. Nat. Rev. Genet. 2014, 15, 121-132. [CrossRef] [PubMed]

149. Koren, S.; Walenz, B.P.; Berlin, K.; Miller, J.R.; Bergman, N.H.; Phillippy, A.M. Canu: scalable and accurate long-read assembly via adaptive k-mer weighting and repeat separation. Genome Res. 2017, 27, $722-736$. [CrossRef] [PubMed]

150. Lim, Y.W.; Cuevas, D.A.; Silva, G.G.Z.; Aguinaldo, K.; Dinsdale, E.A.; Haas, A.F.; Hatay, M.; Sanchez, S.E.; Wegley-Kelly, L.; Dutilh, B.E.; et al. Sequencing at sea: challenges and experiences in Ion Torrent PGM sequencing during the 2013 Southern Line Islands Research Expedition. PeerJ 2014, 2, e520. [CrossRef]

(C) 2019 by the authors. Licensee MDPI, Basel, Switzerland. This article is an open access article distributed under the terms and conditions of the Creative Commons Attribution (CC BY) license (http://creativecommons.org/licenses/by/4.0/). 